Running head: NOVEL ODDBALL PARADIGM IN VIRTUAL REALITY

\title{
Real brains in virtual worlds: Validating a novel oddball paradigm in virtual reality
}

Jonathan W. P. Kuziek ${ }^{\text {a }}$, Abdel R. Tayem ${ }^{a}$, Jennifer I. Burrell ${ }^{a}$, Eden X. Redman ${ }^{\text {a }}$, Jeff Murray ${ }^{\mathrm{c}}$, Jenna Reinen $^{\mathrm{c}}$, Aldis Sipolins ${ }^{\mathrm{c}}$, Kyle E. Mathewson ${ }^{\mathrm{a}, \mathrm{b}}$

${ }^{a}$ Department of Psychology, Faculty of Science, University of Alberta,

${ }^{b}$ Neuroscience and Mental Health Institute, Faculty of Medicine and Dentistry, University of Alberta

${ }^{c}$ IBM Research: Education \& Cognitive Sciences

Type of article: Full length research paper

Number of text pages: 30 (including references)

\section{Number of figures: 7}

\section{Number of tables: 5}

\section{Corresponding Author:}

Kyle E. Mathewson, Ph.D.

Assistant Professor of Cognitive Neuroscience

Department of Psychology

P-455 Biological Sciences

University of Alberta

Edmonton, AB, Canada, T6G 2E9

kmathews@ualberta.ca 
1 Electroencephalography (EEG) research is typically conducted in controlled laboratory settings. This

2 limits the generalizability to real-world situations. Virtual reality (VR) sits as a transitional tool that

3 provides tight experimental control with more realistic stimuli. To test the validity of using VR for event-

4 related potential (ERP) research we used a well-established paradigm, the oddball task. For our first

5 study, we compared VR to traditional, monitor-based stimulus presentation using visual and auditory

6 oddball tasks while EEG data was recorded. We were able to measure ERP waveforms typically

7 associated with such oddball tasks, namely the P3 and earlier N2 components, in both conditions. Our

8 results suggest that ERPs collected using VR head mounted displays and typical monitors were

9 comparable on measures of latency, amplitude, and spectral composition. In a second study, we

10 implemented a novel depth-based oddball task and we were able to measure the typical oddball-related

11 ERPs elicited by the presentation of near and far stimuli. Interestingly, we observed significant

12 differences in early ERPs components between near and far stimuli, even after controlling for the effects

13 of the oddball task. Current results suggest that VR can serve as a valid means of stimulus presentation in

14 novel or otherwise inaccessible environments for EEG experimentation. We demonstrated the capability

15 of a depth-based oddball in reliably eliciting a P3 waveform. We also found an interaction between the

16 depth at which objects are presented and early ERP responses. Further research is warranted to better

17 explain this influence of depth on the EEG and ERP activity.

19 Keywords: EEG; ERP; Virtual Reality; Depth; 3D 
NOVEL ODDBALL PARADIGM IN VIRTUAL REALITY

\section{Introduction}

Electroencephalography (EEG) research is typically conducted in a highly controlled laboratory setting. However, this often limits the generalizability of results to real-world situations. Contemporary research has shown that alternative means of stimulus presentation such as virtual or augmented reality can yield results comparable to traditional EEG methods. In order to identify ways to make EEG experimentation more accessible and generalizable, here we test the use of a virtual reality head mounted display to elicit ERP components of interest in an oddball task.

Recently there has been an increase in EEG experimentation moving into more ecologically relevant environments. With this increase, there have been several notable attempts to find alternative means of stimulus presentation. Recent research into mobile EEG (Kuziek, Shienh, \& Mathewson (2017); Scanlon, Townsend, Cormier, Kuziek, \& Mathewson (2019); Debener, Minow, Emkes, Grandras, \& De Vos (2012); has demonstrated methods to increase experimental generalizability by bringing EEG techniques into new environments. While mobile EEG experimentation is valuable and addresses many challenges facing modern cognitive neuroscience, it can be limited by such practical boundaries as participant safety in potentially hazardous environments and by the presentation of certain types of stimuli remaining unfeasible. Virtual Reality (VR) allows for the presentation of otherwise inaccessible environments while retaining a high level of experimental flexibility and control.

VR has over two decades of history in research, having been incorporated into psychology, neuroscience, and medical experimentation (Pugnetti et al., 1998; Sawaragi \& Horiguchi, 1999; Lee et al., 2003). However, with recent advances in VR technology, techniques utilizing VR research are rapidly changing. VR has recently seen use in a wide range of research extending from remediation following stroke (Choi, Ku, Lim, Kim, \& Paik, 2016; Ho et al., 2019), to treatment for fear of public speaking (Safir, Wallach, \& Bar-Zvi, 2012; Anderson et al., 2013), and PTSD (Rothbaum et al., 2014; Smith et al., 2015). Other studies have begun to employ the use of VR in cognitive neuroscience, allowing for the creation of new paradigms, most notably in embodied cognition to which there are few other methods 
available to elicit relevant participant states (Argelaguet, Hoyet, Trico, \& Lécuyer, 2016). Recently, VR

47 has been increasingly used with concurrent brain recording, studies into the effects of VR have primarily used EEG as its measurement of effects. Recent studies such as Banaei et al., (2017) and Stolz, Endres, and Mueller (2019), have investigated VR while using mobile EEG to create safer immersive environments to investigate and explore.

VR research is still in its infancy; as such, there are few paradigms in research that have been appropriately validated. Dankert, Heil and Pfeiffer (2013) studied stereo vision and acuity in VR. In the study, they used VR to present animated dots to the participants, using a concave screen and projector to create a sense of immersion, and those with stereo vision were able to see a shape emerging. However, the limitations of the screen size allowed for pixilation to occur, limiting the validity of the results. The impact of VR hardware itself on a given experiment remains unclear. Results such as those from Dankert,

57 Heil, \& Pfeiffer (2013), as well as others, demonstrate the lack of systematic testing of the combination of 58 immersive VR, projective VR, and EEG. Harjunen, Ahmed, Jacucci, Ravaja and Spapé (2017) attempted to investigate the differences between VR and non-VR conditions, concluding that "VR headsets can safely be used in ERP research without compromising the reliability of EEG recordings." However, their

61 conclusion was based on the lack of "adverse effects" to the ERPs, not the unexpected seemingly

62 auspicious results of an increased P3 and signal-to-noise-ratio. Other studies such as Strickland and

63 Chartier (1997) and Bayliss and Ballard (2000) investigated the effects of VR on EEG data. However, due

64 to the great leaps in technology, as well as the decrease in size and weight of VR systems over the past 20

65 years, these papers are no longer representative and testing with modern equipment is needed for further 66 validation. 
71 (Exp. 2) in which our goal was to demonstrate that a novel VR-specific depth-based oddball task can

72 elicit the typical oddball-related $\mathrm{P} 3$ response. We were also interested to see whether there are discernible 73 differences in ERPs to stimuli shown at near versus far depths.

\subsection{Method - Exp. 1}

75

76

77

78

\subsection{Participants}

A total of 24 members of the university community participated in the experiment (mean age $=$ 23.33; age range $=18-32 ; 9$ males). Participants were all right-handed, and all had normal or corrected normal vision and no history of neurological problems. All participants gave informed consent and were either given course credit for an introductory psychology course or else were given an honorarium of $\$ 10 /$ hour for their time. The experimental procedures were approved by the internal Research Ethics Board of the University of Alberta.

\subsection{Materials \& Procedure}

A virtual environment was displayed to the participant with either a ViewPixx monitor (non-VR condition) or an HTC VIVE virtual reality headset (VR condition). Participants completed four oddball tasks, an auditory and a visual oddball task in each of the VR and non-VR environments. Task order, auditory or visual oddball, was counterbalanced and randomised. The order of the stimulus presentation, non-VR or VR, was counterbalanced and alternated between participants such that participant 1 would complete non-VR first, participant 2 would complete VR first, participant 3 would complete non-VR first, and so on. Participants would complete both VR or non-VR tasks before switching to the second condition (eg. both the auditory and visual oddball tasks would be completed in VR followed by completing both oddball tasks in non-VR). During each trial either a target or standard stimulus was presented, with a $20 \%$ chance for target to be presented and an $80 \%$ chance for a standard to be presented. Participants were asked to sit still and fixate on a white cross presented directly in front of them that stayed constant throughout the auditory task. In the auditory task two tones at different frequencies were played, $1000 \mathrm{~Hz}$ for standard tones and $1500 \mathrm{~Hz}$ for target tones. Each tone was sampled at $44100 \mathrm{~Hz}$, 
97

98

99

100

101

102

103

104

105

106

107

108

109

110

task participants were again told to focus on the fixation cross while also attending to two black orbs located to the left and right of fixation. At the beginning of each trial, these orbs would flash one of two colours, either blue for targets or green for standards. The orbs would remain coloured for approximately $1.4 \mathrm{~s}$ until returning to black. Participants were instructed to move only their right hand to press the spacebar on a keyboard placed in front of them each time a target was presented. Following the presentation of a standard, participants were instructed to withhold any response. For both the auditory and visual oddball tasks, the time between each stimulus onset was randomly selected from an evenly distributed array of times between 1.5-2 s. Response times were collected until $1.4 \mathrm{~s}$ following target onset. Figure 1A and 1B show how the auditory and visual oddball tasks were presented, respectively.

\section{Insert Figure 1 About Here}

For the VR condition, the size of the fixation cross was $(0.02 \mathrm{~m}, 0.046 \mathrm{~m}, 0.02 \mathrm{~m})$ and location was $(-0.2 \mathrm{~m}, 1.45 \mathrm{~m},-0.275 \mathrm{~m})$, reported in $(\mathrm{x}, \mathrm{y}, \mathrm{z})$ coordinates with the default units in Unity being meters. The program and source code can be accessed freely from the following repository:

github.com/APPLabUofA/VR_Depth. The size of each orb was $(0.25 \mathrm{~m}, 0.25 \mathrm{~m}, 0.25 \mathrm{~m})$. The location of the left orb was $(-0.58 \mathrm{~m}, 1.45 \mathrm{~m},-0.275 \mathrm{~m})$ and the location of the right orb was $(0.18 \mathrm{~m}, 1.45 \mathrm{~m},-0.275$ $\mathrm{m})$. The location of the participant in the virtual environment was approximately $(-0.189 \mathrm{~m}, 1.3302 \mathrm{~m},-$ $1.5664 \mathrm{~m})$. The size of the fixation cross was approximately $(0.02 \mathrm{~m}, 0.04 \mathrm{~m}, 0.02 \mathrm{~m})$, located in the center of our environment $(0 \mathrm{~m}, 0 \mathrm{~m}, 0 \mathrm{~m})$. For the non-VR condition, the fixation measured 1.1 by 1.1 degrees and was presented in the center of the screen. Each orb was 5.9 degrees tall by 5.6 degrees wide, presented 8.5 degrees to the left and right of fixation. Stimuli during the VR condition were displayed using an HTC VIVE headset which contains two PenTile OLED displays with a maximum resolution of 2160 x 1200 pixels and a refresh rate of $90 \mathrm{~Hz}$. For the non-VR condition participants were seated 57-cm away from a ViewPixx/EEG LED monitor running at a resolution of 1920 x 1080 pixels and a refresh rate of $120 \mathrm{~Hz}$ with simulated-backlight rastering. Each participant completed 250 trials for each oddball experiment and condition. Stimuli were presented using a Windows 7 PC running Unity 2017.1.0. Auditory stimuli were presented using a pair of Logitech Z130 speakers kept at a constant volume level. 
123

124

125

126

127

128

129

130

131

132

133

134

135

136

137

138

139

140

141

142

143

144

145

146

147

148

Video output was via an Asus Striker GTX1070, and audio was output via an Asus Xonar DSX sound card. Coincident in time with sound and image onset, 8-bit TTL pulses were sent to the EEG amplifier by a parallel port cable connected to the ViewPixx monitor to mark the data for ERP averaging. The experiment was displayed to the ViewPixx monitor in both conditions to allow the experimenter to confirm the task had properly started at the beginning of each condition, and to send TTL pulses to mark stimulus onset within the recorded EEG data. We tested the delay between stimulus onset and TTL pulse onset for the auditory and visual oddball tasks. While there was a noticeable delay for the auditory task $($ Mean $=169.5 \mathrm{~ms} ; \mathrm{SD}=16.1 \mathrm{~ms})$, compared to the visual task $\left(\right.$ Mean ${ }_{\mathrm{VR}}=4.8 \mathrm{~ms} ; \mathrm{SD}_{\mathrm{VR}}=3.0 \mathrm{~ms}$; Mean $_{\text {Non-VR }}=12.9 \mathrm{~ms} ; \mathrm{SD}_{\mathrm{Non}-\mathrm{VR}}=1.4 \mathrm{~ms}$ ), these delays are consistent. We believe the auditory delays are due to auditory jitter introduced by the Windows and Unity software. Please note that auditory delays were not measured separately for the VR and non-VR conditions because the auditory stimuli were presented in Unity for both conditions.

\subsection{EEG recording}

During each oddball task, EEG data was collected from participants using passive, wet, lowimpedance electrodes (actiCAP passive electrodes kept below $5 \mathrm{k} \Omega$ ). Inter-electrode impedances were measured at the start of each experiment. All electrodes were arranged in the same 10-20 positions (O1, P7, T7, P3, C3, F3, Pz, Cz, Fz, P4, C4, F4, P8, T8, O2). A ground electrode was used, positioned at AFz. $\mathrm{Ag} / \mathrm{AgCl}$ disk electrodes were used, with SuperVisc electrolyte gel and mild abrasion with a blunted syringe tip used to lower impedances. Gel was applied and inter-electrode impedances were lowered to less than $5 \mathrm{k} \Omega$ for all electrode sites. Electrode impedance was checked several times throughout the experiment; following placement of the electrodes and EEG cap on the participant, after the VR headset was placed on the participant, and after each oddball task was completed. EEG was recorded online and referenced to an electrode attached to the left mastoid. Offline, the data were re-referenced to the arithmetically derived average of the left and right mastoid electrodes.

EEG data was recorded with a Brain-Amp 16-channel amplifier connected to a laptop running the BrainVision Recorder software, using identical settings across all participants. In addition to the 15 EEG 
sensors, two reference electrodes, and the ground electrode, vertical and horizontal bipolar EOG was

recorded from passive $\mathrm{Ag} / \mathrm{AgCl}$ easycap disks. $\mathrm{EOG}$ electrodes were affixed vertically above and below

the left eye and affixed horizontally $1 \mathrm{~cm}$ lateral from the outer canthus of each eye. The participant's

152 skin was cleaned using Nuprep (an exfoliating cleansing gel) before the placement of the electrodes,

153 electrolyte gel was used to lower the impedance of these electrodes to under $5 \mathrm{k} \Omega$ in the same manner as

154 previously mentioned. These bipolar channels were recorded using the AUX ports of the Brain-Amp

155 amplifier. Data were digitized at $1000 \mathrm{~Hz}$ with a resolution of 24 bits and hardware filtered online with a

156 low cut-off of $10.0 \mathrm{~s}$, a high cut-off of $250 \mathrm{~Hz}$, an additional online software cut-off of $50 \mathrm{~Hz}$, and a time

157 constant of 1.59155 s. Each experiment was completed in a dimly lit, sound and radio frequency-

158 attenuated chamber from Electromedical Instruments, with copper mesh covering the window. The only

159 electrical devices in the chamber were an amplifier, speakers, keyboard, mouse, monitor, and VR headset.

160 The monitor and HTC VIVE headset ran on DC power from outside the chamber, the keyboard and

161 mouse were plugged into USB extenders outside the chamber, and the speakers and amplifier were both

162 powered from outside the chamber. The HTC VIVE system's two motion sensors, known as lighthouses,

163 are mounted in the chamber in front of and to the left of the participant, as well as behind and to the right,

164 and are raised 3 feet above the average participant's head level. They were connected to power outside of

165 the chamber, and they emit infrared pulses at $60 \mathrm{~Hz}$ which are detected by the VIVE headset to locate

166 itself in 3D space. The fan for the chamber was turned on, and nothing was plugged into the internal

167 power outlets. Any devices transmitting or receiving radio waves (e.g., cell phones) were either turned off

168 or removed from the chamber for the duration of the experiment.

\subsection{EEG analysis techniques}

Analyses were computed in Matlab R2018a using EEGLAB (Delorme \& Makeig, 2004) and

171 custom scripts. The timing of the TTL pulse was marked in the recorded EEG data and used to construct

$1721200 \mathrm{~ms}$ epochs time locked to the onset of standard and target tones with the average voltage in the first

$173200 \mathrm{~ms}$ baseline period, subtracted from the data for each electrode and trial. To remove artifacts due to

174 amplifier blocking and other non-physiological factors, any trials with a voltage difference from baseline 
175 larger than $+/-1000 \mu \mathrm{V}$ on any channel (including eyes) were removed from further analysis. At this

176 time, a regression-based eye-movement correction procedure was used to estimate and remove the

177 artifact-based variance in the EEG due to blinks as well as horizontal and vertical eye movements

178 (Gratton, Coles, \& Donchin, 1983). After identifying blinks with a template-based approach, this

179 technique computes propagation factors as regression coefficients predicting the vertical and horizontal

180 eye channel data from the signals at each electrode. The eye channel data is then subtracted from each

181 channel, weighted by these propagation factors, removing any variance in the EEG predicted by eye

182 movements. Artifact rejection was again performed except for this second round of artifact rejection

183 removed trials containing a voltage difference of $+/-500 \mu \mathrm{V}$. Baseline correction was performed a second

184 time following the second artifact rejection.

Trial-averaged ERPs were derived and waveforms were compared. Analysis on the N2 and P3

waveforms was done using difference waveforms, computed by subtracting the ERPs for standards from all further analysis: Auditory N2 = 324-366 ms; Auditory P3 = 427-631 ms; Visual N2 = 88-106 ms;

194 Visual P3 = 300-570 ms. A one-tailed t-test was performed to understand if a significant N2 or P3 peak

195 was observed, while a two-tailed t-test was performed to compare peaks across devices, with $\alpha$ set to 0.05

196 for all analyses. We also employed Bayesian statistics, which has been proposed as a more-informative

197 alternative to statistical tests involving p-values (Jarosz \& Wiley, 2014; Wagenmakers, Love, et al., 2018;

198 Wagenmakers, Marsman, et al., 2018) to directly test our null hypothesis that there is no significant

199 difference in the EEG recordings between our devices. Bayesian analysis was done using version 0.8.6 of 
the JASP software (JASP Team, 2019), which is a powerful tool for Bayesian statistics (Wagenmakers,

201 Love, et al., 2018; Wagenmakers, Marsman, et al., 2018).

202

\subsubsection{Single trial noise}

We then estimated the amount of noise in the data on individual trials in two ways. First, we computed the average frequency spectra of the baseline period in each EEG epoch. For each participant, we randomly selected 180 of their artifact-free standard trials from electrode Pz. For each trial, we computed a Fast Fourier Transform (FFT) by symmetrically padding the 1200 time-point epochs with zero to make a 2048-point time series for each epoch, providing frequency bins with a resolution of 0.488 Hz. Each participant's 180 spectra are then averaged together to compute participant spectra, which were then combined to form grand average spectra. To compute a second and related estimate of the noise on single trial EEG epochs, we randomly selected 180 standard tone epochs for each participant and computed the root mean square (RMS) of the baseline period on each trial. We used the $200 \mathrm{~ms}$ baseline period (200 time points) prior to trigger onset to avoid the influence of any evoked ERP activity on the RMS measurement. The RMS is a measure of the average absolute difference of the voltage around the baseline and is a good estimate of single trial noise in the EEG data. Smaller RMS values would suggest fewer voltage differences around the baseline and, therefore, less noise present in the data. For each trial, we average the RMS values for each EEG electrode, then averaged over trials for each participant, then computed the grand average RMS across participants (as in Laszlo, Ruiz-Blondet, Khalifian, Chu, \& Jin, 2014). To estimate the distribution of RMS in our data for each device, we employed a permutation test in which 180 different epochs were selected without replacement for each participant on each of 10,000 permutations. For each of these random selections, and each electrode, we computed and recorded the grand average single trial RMS. To quantify the level of noise in the participant average ERPs, we again employed a permutation test of the RMS values in the baseline period. In this ERP version, for each of the 10,000 permutations, we averaged the 180 standard trials that were randomly selected without replacement from the larger pool of that participant's artifact free trials for each device. We then 
computed the RMS of the resultant 200 time points of the ERP baseline. We averaged these RMS values over all EEG electrodes, then computed a grand average across participants.

\subsubsection{ERP power}

To compare the ERP statistical power as a function of the number of trials used for both the P3 and $\mathrm{N} 2$, we used another permutation procedure in which we varied the number of trials contributing to the ERP average while keeping the 4 to 1 ratio of standard to target trials (Mathewson, Harrison, \& Kizuk, 2017). Trial numbers were varied from 4 standards and 1 target trial, by 20 standard trials, up to 180 standard and 36 target trials, separately for each of the two stimulus types. For each number of trials, 10,000 permutations were randomly selected from the total pool without replacement. For each permutation, the selected single trials were averaged to create participant ERPs separately for target and standard tones. The difference between target and standard tones was then computed at electrode Fz (N2) and electrode $\mathrm{Pz}(\mathrm{P} 3)$, and these simulated participant average ERP differences were compared to a null distribution with a standard one-tailed t-test.

\subsection{Behavioural Results}

Following artifact rejection similar trial counts were obtained for targets and standards as shown in Table 1. Figure 1C shows the response times to target stimuli during the auditory and visual oddball tasks. Results of a two-tailed t-test suggest no difference in response times between the auditory VR $($ Mean $=612.521 \mathrm{~ms} ; \mathrm{SD}=128.375 \mathrm{~ms})$ and non-VR conditions $($ Mean $=598.212 \mathrm{~ms} ; \mathrm{SD}=123.112 \mathrm{~ms}$; $\mathrm{t}(23)=-0.519 ; \mathrm{p}=0.609)$ but a significant difference between the visual VR (Mean $=500.293 \mathrm{~ms} ; \mathrm{SD}=$ $124.616 \mathrm{~ms}$ ) and non-VR conditions (Mean $=479.360 \mathrm{~ms} ; \mathrm{SD}=127.372 \mathrm{~ms} ; \mathrm{t}(23)=-2.476 ; \mathrm{p}=0.021)$.

\section{Insert Table 1 About Here}

\subsection{ERP Analysis}

Figure 2 shows the grand average ERPs from electrode $\mathrm{Pz}$ and $\mathrm{Fz}$ following standard and target tones during the A) auditory and B) visual oddball tasks. A P3 response can be observed following targets in both oddball tasks but an N2 response is only strongly observed following auditory targets. Also shown 
are the difference waveforms at electrode $\mathrm{Fz}$ and $\mathrm{Pz}$ for the A) auditory and B) visual oddball tasks. The difference waveforms were calculated by subtracting the ERPs for standards from the ERPs following targets. A large negative deflection at electrode Fz can be observed for the auditory N2. By comparison, a much smaller negative deflection is observed for the visual N2. A distinct P3 response, signified by a large positive-going deflection, can be observed at electrode Pz for both the auditory and visual oddball tasks. Figure 2 also shows topographies and bar graphs of the averaged ERP effects across the indicated time windows, with similar patterns of activity for both devices in all but the visual N2 region.

\section{Insert Figure 2 About Here}

Table 2A shows the results of the one-tailed $t$-test for the N2 and P3 waveforms at electrode Fz and Pz respectively. Results comparing the waveforms between the VR and non-VR condition are shown in Table 2B. Hedge's $g$ was used to estimate effect size, which was calculated using version 1.5 of the Measures-of-Effect-Size toolbox for Matlab (Hentschke \& Stüttgen, 2011). Results of the Bayesian onesample and paired-sample t-tests show how much our data supports the alternative hypothesis for each

264 test, either being a significant difference from 0 for the one-sample t-tests of a significant difference between the VR and non-VR conditions for the paired-sample t-tests. Support for the alternative hypothesis is reported as a Bayes Factor $\left(\mathrm{BF}_{10}\right)$ with numbers greater than 1 indicating the data is more likely under the alternative hypothesis and numbers less than 1 indicating support for the null hypothesis.

\section{Insert Table 2 About Here}

\subsection{Single Trial Noise}

Grand average spectra are shown in Figure $3 \mathrm{~A}$ and $3 \mathrm{C}$, along with topographies showing the

271 average spectra between $0.5-3 \mathrm{~Hz}, 4-7 \mathrm{~Hz}, 8-12 \mathrm{~Hz}$, and 13-30 Hz. Histograms of the single trial RMS

272 values computed for each permutation, along with bar graphs of the mean and standard deviation, are

273 shown in Figure 3B and 3E for the auditory and visual oddball tasks respectively. Also shown are the

274 grand average RMS values computed in each of the 10,000 permutations for both conditions, along with a

275 bar graph of the mean and standard deviation. Both the single trial and grand average RMS distributions

276 suggest less noise was present during the non-VR condition compared to the VR condition. 
NOVEL ODDBALL PARADIGM IN VIRTUAL REALITY

Insert Figure 3 About Here

\subsection{ERP Power}

Figure 4 plots the proportion of the 10,000 permutations in which the $t$-statistic passed the significance threshold, as a function of the number of samples in each permutation. The P3 and N2 waveforms required a similar number of trials to reach significance with $80 \%$ power, although as expected the N2 waveform did not reach significance for either condition during the visual oddball task. For the N2 waveform during the auditory task, approximately 37 and 26 trials were needed for the VR and non-VR conditions respectively. For the P3 waveform during the auditory task about 6 trials were needed to reach significance for both conditions. For the visual oddball task about 4 trials were needed for the P3 waveform to reach significance in both conditions.

\section{Insert Figure 4 About Here}

\section{Discussion - Exp. 1}

The goal of the first experiment was to expand on a recent trend in current literature focusing on EEG generalization and to establish validity in the use of VR technology in basic research in cognitive neuroscience, particularly those involving the oddball paradigm.

Behavioural results indicate there is a small but significant difference between the non-VR and VR in the visual oddball task. Overall slower responses to 3D stimuli may be the result of increased visual information, such as depth, being presented to participants. Another explanation could be the distraction of wearing a VR headset causes a slowing of response times as well. However, despite these differences, ERP waveforms derived from stimuli presented in the VR and non-VR conditions were found to be nearly identical during the time windows relevant to the oddball task. Taken together these results demonstrate the versatility of VR and its applicability in cognitive psychology. It is important to note the clarity in the P3 response despite introduced sources of noise in the VR condition. The first of which is the addition of VR equipment which may introduce electrical noise and presents an added physical challenge to participants with added weight, which may lead to extra muscle artifacts due to neck tension, 
or increased pressure on electrodes directly beneath the headset. The second source of noise pertains to the different levels of engagement within the environment, differing levels of processing may be required to interpret a more immersive and realistic scene, however, this may be counteracted by virtue of the VR environment itself presenting as more engaging to the viewer and yielding more readily available attentional resources. Lastly, there are several differences between non-VR and VR stimuli in terms of 307 viewing quality: resolution, refresh rate, and field of view.

Both systems showed the expected ERP, P3, and N2 waveforms along with similar topographies, with the greatest activity focused on electrodes Pz and Fz respectively. Bayesian paired t-tests further support that it is likely the data falls under the null hypothesis suggesting no difference between recording techniques for the N2 and P3. However, we did observe some differences in the amount of noise during baseline, as indicated by the differences in the RMS distributions for both systems. Despite the apparent

313 difference in noise between the VR and non-VR conditions, similar statistical power, frequency

314 distributions, and ERP waveforms were observed between both systems. However, other results have 315 shown that any observed difference between RMS noise has minimal impact on the derived ERPs and 316 their statistical power.

Both devices showed the expected 1/f frequency structure in the spectral data, as well as the 318 typical peak in the alpha frequency range between 8 and $12 \mathrm{~Hz}$ (Mathewson et al., 2011) along with 319 another peak at about $7 \mathrm{~Hz}$. At frequencies below approximately $15 \mathrm{~Hz}$, both conditions show similar 320 spectra but start to deviate past $15 \mathrm{~Hz}$. This difference could be due to several sources. The VR headset

321 likely put pressure on several frontal electrodes, along with any electrodes directly under the headset 322 straps. Increased facial and muscle strain was also likely present for the VR condition due to the weight 323 and comfort of the headset. While only the muscle-related sources of noise would likely be present in the 324 frequency range we are interested in (Hagemann \& Naumann, 2001; Goncharova,, McFarland, Vaughan, 325 \& Wolpaw, 2003), increased electrical sources of noise would still be present during the VR condition 326 and likely influence frequencies far beyond our $30 \mathrm{~Hz}$ maximum. Furthermore, it is worth noting there is 
a consistent trend in the commercial VR industry to provide progressively lighter VR head mounted displays; there will likely be less contamination due to muscle artifacts with lighter models.

We were able to demonstrate that a commercial HTC Vive headset, a relatively inexpensive and fully immersive VR device, can present oddball stimuli comparably to a research-standard non-VR monitor. We were able to show that the ERPs derived from typical auditory and visual oddball tasks are comparable when stimuli are presented using VR and non-VR methods. We then looked to explore stimuli relevant to 3D environments. In the next experiment, we explore the addition of a new dimension, depth, to the standard visual oddball task, a task that cannot be replicated on a traditional monitor.

\section{Introduction- Exp. 2}

Results from Exp.1 indicate that the ERPs from stimuli presented from VR headsets are comparable to those presented with a traditional non-VR monitor. In the following experiment, we hoped specific to VR itself. We translated the typical oddball paradigm into a novel VR-specific task by specifically modulating the domain of depth. Using this depth-based oddball, we compared ERPs to near

341 and far standards and targets in an attempt to elicit a P3 waveform similar to other recent adaptations of 342 the standard oddball task (Raz, Dan, \& Zysberg, 2014). The oddball paradigm has been shown to be 343 sensitive to changes in several modalities, ranging from sensitivity to basic visual elements of stimuli 344 such as colour (Fonteneau \& Davidoff, 2007), to higher-level processes such as emotion (Raz \& Zysberg, 345 2014).

Depth has traditionally been studied by moving a stimulus or monitor while covering the

347 participant's eyes but does not allow for perceived size (retinal size) to remain constant. This effect

348 contributes to the ease in which participants are able to identify the near or far object due to extraneous

349 depth cues (Bohr \& Read, 2013). When using VR, object size can be controlled proportionally to keep

350 retinal size constant at varying depths with respect to the viewer. Other potential depth cues, such as

351 shadows, may also be controlled in a VR environment. Naceri, Moscatelli, \& Chellali (2015) studied

352 depth perception when perceived size was not available as a depth cue. They found that while keeping the 
size of the objects constant, participants used convergence, binocular disparity and accommodation cues

to allow for depth recognition. Our study followed this principle and kept the perceptual size consistent across different depths.

\section{Method - Exp. 2}

\subsection{Participants}

A total of 18 members of the university community participated in experiment two (mean age $=21.60$ age range $=17-43 ; 8$ males). Participants were all right-handed, and all had normal or corrected normal vision and no history of neurological problems. All participants gave informed consent, were given course credit for their time, and the experimental procedures were approved by the internal Research Ethics Board of the University of Alberta.

\subsection{Materials \& Procedure}

All hardware remained the same as in the VR condition described in Exp.1. Each participant completed a visual oddball task in VR where orbs were placed either close to the participant (Near) or further away (Far). The size of the near orb was $(0.10 \mathrm{~m} 0.10 \mathrm{~m}, 0.10 \mathrm{~m})$ and the location was $(-0.2 \mathrm{~m}$,

$3671.45 \mathrm{~m},-0.162 \mathrm{~m})$. The size of the far orb was $(1.0 \mathrm{~m}, 1.0 \mathrm{~m}, 1.0 \mathrm{~m})$ and the location was $(-0.29 \mathrm{~m}, 2.55$

$368 \mathrm{~m}, 12.83 \mathrm{~m})$. The location of the participant in the virtual environment was identical to experiment one (-

$3690.189 \mathrm{~m}, 1.3302 \mathrm{~m},-1.5664 \mathrm{~m})$. The size of the fixation cross was approximately $(0.02 \mathrm{~m}, 0.04 \mathrm{~m}, 0.02$

$370 \mathrm{~m})$, located at $(-0.5 \mathrm{~m},-6.49 \mathrm{~m},-0.04 \mathrm{~m})$. The orbs participants responded to were considered targets and

371 orbs that participants were not responding to were considered standards, in-line with the typical oddball

372 paradigm. The experiment was divided into two conditions, a Near condition where participants

373 responded when the nearest orbs were presented, and a Far condition where participants responded to the

374 farthest orbs. The conditions henceforth are referred to by the location of the target stimuli Near and Far, 375 respectively. Targets and standards were presented in the same 20\% - 80\% ratio as described in Exp. 1 for 376 both Near and Far conditions. 
Participants completed each condition twice, responding to near and far targets in separate blocks.

Both orbs were centred and in line with the central fixation cross and both orbs were perceived to be

379 identical in size. In other words, the farther orb was larger than the near orb but both orbs were perceived

380 to be the same size by the participant, only the relative retinal disparity would be modulated. Participants

381 placed their head in a chin rest to reduce noise caused by muscle strain as well as to remove extraneous

382 depth cues due to head movement and position, such that the only distinguishing factor in the VR

383 environment was relative depth. Task order, whether they were responding to near or far targets, was

counterbalanced and alternated between participants such that participant 1 completed both Near

condition blocks first, participant 2 completed the Far condition first, participant 3 completed the Near

condition first, and so on. Participants were instructed to move only their right hand to press the spacebar

on a keyboard placed in front of them each time a target stimulus was presented. Following the

presentation of a standard stimulus, participants were instructed to withhold any response. During each

To estimate adduction and abduction of the eyes to stimuli of different depths in the task, the position of the horizontal EOGs were modified and placed over of the medial and lateral rectus muscles of the left eye.

\section{Insert Figure 5 About Here}

\section{Results - Exp. 2}

\subsection{Behavioural Results}

Trial counts for targets and standards in each condition, following artifact rejection, are shown in

Table 3. Figure 5C shows the mean response times following targets in the Near Targets and Far Targets 
$($ Mean $=593.566 \mathrm{~ms} ; \mathrm{SD}=175.966 \mathrm{~ms})$ and near targets $($ Mean $=560.338 \mathrm{~ms} ; \mathrm{SD}=161.841 \mathrm{~ms} ; \mathrm{t}(17)=$ $-1.950 ; \mathrm{p}=0.068)$.

\section{Insert Table 3 About Here}

405

\subsection{ERP Analysis}

Figure 6A shows the grand average ERPs from electrode $\mathrm{Pz}$ and $\mathrm{Fz}$ following standard and target tones during the Near and Far conditions of the depth oddball task. A noticeable P3 response can be observed following targets in both conditions. Figure 6B shows difference waveforms for standards and targets at electrode Fz and Pz. These waveforms were constructed by subtracting Near standards from Far standards and Near targets from Far targets to observe any potential differences between Near and Far stimuli. Deflections in these difference waveforms suggest differences in ERP activity following Near/Far standards and Near/Far targets. Such deflections are typically occurring early in the difference waveform (up to $500 \mathrm{~ms}$ post-stimulus onset) with target stimuli showing the greatest difference in activity between the near and far depths. Figure 6C shows the difference waveforms at electrode Fz and $\mathrm{Pz}$ for the Near and Far conditions. These waveforms were calculated by subtracting the ERPs for standards from the ERPs following targets. In the case of the Near condition, ERPs to the far, standard stimuli were subtracted from the ERPs following the near, target stimuli. Difference waveforms for the Far condition were generated by subtracting ERPs following Near, standard stimuli from ERPs generated after the Far, target stimuli. The boundaries for the P3 time window was selected in a similar manner as described for experiment one. We ran a one-tailed t-test across each time point of the participant grand-average ERP for both the Near and Far conditions, with $\alpha$ set to 0.005 , to determine large, consistent regions of significance. Significant regions that overlapped in both Near and Far conditions were used for our P3 time window. Based on this technique we used 349-623 ms for our P3 time window. A large P3 response during this time window at electrode $\mathrm{Pz}$ can be observed in the difference waveforms for both conditions. Interestingly, two distinct, opposing patterns of activity between our conditions can be seen prior to the onset of the $\mathrm{P} 3$ response. These patterns of activity at electrode $\mathrm{Pz}$, along with the $\mathrm{P} 3$ waveform, were used to generate three time windows that will be used for all further analysis (175-225 ms; $225-300 \mathrm{~ms}$; 
349-623 ms). Electrode Pz was chosen as we expected the P3 waveform would be greatest at this electrode and, as such, any differences between our Far and Near targets would also be greatest.

Table 4 shows the results of the one-tailed $t$-tests, effect size measurements, and Bayesian onetailed $t$-tests for the difference waveforms. Table 4A shows the results of a one-tailed t-test comparing the standard and target difference waveforms from Figure 6B to zero. A right or left tailed t-test was

434 performed based on the mean voltage of each time window. The results suggest a significant difference 435 between Near and Far conditions at the two early time windows but not the later, P3 time window. A 436 similar pattern can also be observed between Near and Far targets with significant differences observed 437 during the 175-225 ms and 225-300 ms time windows. Table 4B shows results for the difference waveforms generated from the Near and Far conditions. A left or right tailed $t$-test was used based on the mean voltage of each time window. Hedge's $g$ was used to estimate effect size, which was calculated using version 1.5 of the Measures-of-Effect-Size toolbox for Matlab (Hentschke \& Stüttgen, 2011).

441 Results suggest that a significant P3 response is obtained during the 349-623 ms time window for both ms time windows for the Near difference waveform.

\section{Insert Table 4 About Here} suggest that our difference waveforms are not significantly different at the 349-623 ms time window but do differ during the 175-225 ms and 225-300 ms time windows. For the Far Targets - Near Standards

449 difference waveform a positive deflection is observed during the $175-225 \mathrm{~ms}$ time window followed by a 450 negative deflection during the $225-300 \mathrm{~ms}$ time window. An opposing pattern of activity is observed for

451 the Near targets - Far standards difference waveform with a negative deflection during the 175-225 ms 452 time window followed by a positive deflection during the $225-300 \mathrm{~ms}$ time window. Such patterns of 453 activity can also be observed for the standard and target difference waveforms at electrode Pz, as shown 
454 in Figure 6B. Contrary to the ERP plots in Figure 6C, our conditions do not differ during the 225-300 ms

455 time window. The above differences are also consistent with the results presented in Table 4.

\section{Insert Table 5 About Here}

Figure 7 shows a plot of the grand-average ERPs at the HEOG, which is designed to monitor horizontal eye movements. These plots were generated to observe changes in eye movements due to changes in the depths of the stimuli; diverging eye movements were expected for far stimuli and convergent eye movements were expected for near stimuli. Plots of the grand-average standards and targets difference waveforms (as shown in Figure 6) are also shown to compare HEOG changes to ERP changes. A two-tailed t-test was performed at each time point of the HEOG and Pz ERP to understand which time points significantly differ from 0 , with significant tests indicated by pink marks at the bottom of each plot. For these t-tests, $\alpha$ was set to 0.005 . For standards, there is no significant point of difference for the HEOG but for the Pz difference waveform the earliest point occurs $253 \mathrm{~ms}$ post-stimulus. For target stimuli, the earliest significant point of difference is at $179 \mathrm{~ms}$ for the HEOG and $190 \mathrm{~ms}$ for the Pz difference waveform.

\section{Insert Figure 7 About Here}

\section{Discussion - Exp 2.}

To further demonstrate the ability of VR as an experimental tool, we had participants complete a novel, depth-based oddball task. The VR head mounted display provides several advantages compared to a non-VR monitor regarding EEG experimentation such as independent presentation of stimuli to each eye. During the depth oddball task, participants would complete two separate conditions, responding either to the near or far target and withholding responses to the respective standard. Separately presenting stimuli to each eye allowed us to manipulate the sense of depth while also maintaining the angle and subjective size of each orb from the participant's point of view. Using this paradigm, we were able to demonstrate that early ERP components are sensitive to changes in stimulus depth while also eliciting the oddball-related P3 waveform. 
Beyond a $\mathrm{P} 3$ response to targets at both depths, there were several interesting characteristics

480 when comparing the Near and Far conditions. Comparing difference waves at $\mathrm{Pz}$ and $\mathrm{Fz}$ of the Near and

481 Far conditions depicts an interaction of depth with elicited ERPs. Figure 6B summarizes these

482 differences, particularly at Pz, where the early waveform components at $175-225 \mathrm{~ms}$ (first window) and

483 225-300ms (second window) vary significantly for both Standard and Target difference waves. Standards

484 show a negative deflection in the first window and a small positive deflection in the second, while targets

485 show the opposite with a large positive deflection in the first window and a negative deflection in the

486 second. These exciting results also show that ERPs differ with depths, supporting the findings of Liu,

487 Meng, Wu and Dang (2015). However, our experiment likely doesn't account for all interaction between

488 the oddball stimulus and depth; further study with an extended experimental design is warranted. One

489 such study may be a passive perceptual experiment involving all non-oddball elements at both depths,

from this we would be able to gauge variance across ERPs that is only due to depth and not task demands.

Our current results support distinct physiological processes for interpreting stimuli across varying is needed.

However, the differential processing of two neutral stimuli that have been size-matched on the

501 retina is not necessarily intuitive. Henderson, Vo, Chunharas, Sprague and Serences (2019) demonstrated 502 that different depths are processed in different retinotopic areas of the brain, mainly in area V3A, and that 503 an encoding model can be used to map the depth of objects on a z-axis, along with their positions in 2D 504 space along vertical and horizontal axes. This provides an explanation of the different depths producing 
different ERPs. While this explanation points out a cognitive mapping perspective on where brain activity changes to these stimuli, it does not identify why such a mapping would be designed or beneficial. In that context, a possible explanation of this phenomenon is the evolutionary relevance of an object's distance to the viewer; responding quickly to a stimulus that is near you tends to be more important than responding quickly to stimuli farther away. We may be physiologically poised to react faster to threatening stimuli

510 that are closer, as seen in the earlier onset of eye movements in HEOGs for near stimuli when compared

511 to far stimuli. The current study may present a generalization of this propensity in detecting and 512 responding to non-threatening stimuli.

Another potential explanation is that differences between Near and Far difference waveforms may depict a perceptual crossing of a distinguishing boundary between peripersonal space (PPS) and extraperipersonal space (EPS), as described by di Pellegrino \& Làdavas, 2015; Làdavas, 2002). PPS refers to a representation of space around an individual that is both malleable and reactive to task

517 demands. There is evidence of distinct regions within this space (de Vignemont \& Iannetti, 2015), and

518 known factors demonstrated to change or modify the personal space (Canzoneri et al., 2013). Differences 519 between the Near and Far conditions, as shown in the difference waves of Figure 6C, may be interpreted 520 as an interaction with distinct regions of peripersonal space - near objects could be perceived to be within 521 PPS and thus is more reactive than a far object that could be perceived to land in EPS.

A possible confound for the differences seen in the P3 of the Near and Far stimuli could be a difference in the complexity of the environment being perceived by the participants, as they could be

524 processing the background and surrounding environment to a greater detail. While this is a valid concern,

525 we don't believe that the complexity of the environment or the background in the Far condition is in any

526 way different to that of the Near condition, given that the participant's position in the environment is

527 identical in both conditions and the same environment is visible to them between all trials of all

528 conditions. What we do propose as a possible explanation for these differences is that following the

529 participant's focus on the fixation cross, the onset of the Far stimulus would happen after a very brief time

530 period where there is a retinal disparity of the far away object, which is then corrected by the eye to focus 
531 on the far object. This retinal disparity is mainly attributed to the difference in depth of the object and not

532 the environment surrounding it, leading us to believe that once again the depth effect explains the

533 differences seen in our P3 responses between the two conditions.

534 With all of these observations and proposed explanations in mind, we must also consider possible 535 interferences and unintended behaviours that could confound these findings. Eye movements that are 536 elicited from stimuli other than the objects presented could interact with the effects seen with the HEOGs.

537 Changes in the exact viewing experience of each participant due to potential image blur, visual acuity,

538 and headset positioning on head shapes and sizes that are inherently different between participants are

539 other potential sources of variability. However, measures were taken to minimize these effects, such as

540 adjusting the interpupillary distance of the lenses in the headset, verbal instructions to maintain eye

541 position on the fixation cross, elimination of stimulus shadows and other such depths cues, and

542 readjusting headset size to best fit each participant.

\section{Conclusions}

Our finding of similar ERPs for traditional and VR tasks in Exp. 1 show the effectiveness of

using a VR head mounted display for ERP research. These results also demonstrate the generalizability of the P3 response, as well as its relevance and applicability in VR. We were also able to demonstrate the

547 flexibility of VR in constructing a novel version of the oddball task, with near and far stimuli eliciting a

548 P3 response along with depth-based differences earlier in the ERP waveform. This research helps to 549 establish the utility of VR in creating new experimental paradigms within a controlled, laboratory setting.

If results can be validated with other tasks without participants being confined to a chin rest,

551 assuming muscle artifacts can be properly accounted for, there may be a basis for conducting indoor

552 mobile VR experiments. Leveraging recent advances in mobile EEG (Aspinall, Mavros, Coyne, \& Roe,

553 2015; Zink, Hunyadi, Huffel, \& Vos, 2016; Scanlon et al., 2019) with advances in the wireless VR

554 industry, there may be space to harness the combination of VR with more mobile experiments within the 555 laboratory. 
To investigate the findings from Exp. 2 regarding differences in the Near and Far difference waves, we are currently running a similar experiment in which we present to the participant five sizematched orbs at different depths. The goal is to determine if there is a gradient-like depth effect, such that we expect the three additional depths to fall sequentially between the nearest and farthest orbs. In future studies, there is room to investigate how other domains interact with the depth oddball. Results may

561 mirror comparable studies of overlapping visual and auditory modalities in the oddball task (Brown,

562 Clarke, \& Barry, 2007; Campanella et al., 2010; Robinson, Ahmar, Sloutsky, Robinson, \& Sloutsky, 563 2010). Brown et al. (2007) showed how auditory and visual oddballs are paired to describe two distinct 564 stages of auditory processing, an early modality-dependent stage and a later context-dependent stage. In 565 addition to auditory dual tasks, we may integrate other visual domains in the depth oddball task such as 566 colour, for example. This method would allow us to ascertain the flow and integration of depth specific 567 information in concert with other modalities.

571 threats affect one's mapping of peripersonal space? Depending on the threat content of the stimuli at

572 various depths, there is reason to believe we could activate different PPS maps altogether (de Vignemont

$573 \&$ Iannetti, 2015). One paradigm to introduce an element of threat while maintaining neutral stimulus

574 presentation would be to offer a monetary sum at the beginning of the experiment. A loss is then accrued

575 from the initial sum if response times fall below a certain baseline-derived threshold. A comparison of

576 adherence to thresholds and resultant ERPs for each Near and Far conditions both with and without threat

577 may reveal interactions of threat with different regions of personal space. The increased flexibility

578 provided by VR systems has the potential to increase the breadth of EEG studies that can be conducted,

579 greatly improving the external validity of EEG experimentation.

580 Here we show that a VR head mounted display is a great tool in developing a wide variety of pre-

581 existing experimental paradigms. Some topics that may readily benefit from a three-dimensional 
582 environment include visual attention, working memory, and learning, allowing for more accurate and

583 realistic models of human navigation. VR as a tool in brain imaging studies offers increased

584 generalizability and flexibility compared to traditional non-VR monitors This is achieved without

585 sacrificing experimental control or introducing highly variable noise artifacts common with using EEG in

586 environments outside of the laboratory. 
NOVEL ODDBALL PARADIGM IN VIRTUAL REALITY

\section{References}

Anderson, P. L., Price, M., Edwards, S. M., Obasaju, M. A., Schmertz, S. K., Zimand, E., \& Calamaras, M. R. (2013). Virtual reality exposure therapy for social anxiety disorder: A randomized controlled trial. Journal of Consulting and Clinical Psychology. https://doi.org/10.1037/a0033559

Amin, H. U., Malik, A. S., Badruddin, N., Kamel, N., \& Hussain, M. (2015). Effects of stereoscopic 3D display technology on event-related potentials (ERPs). 2015 7th International IEEE/EMBS Conference on Neural Engineering (NER). doi:10.1109/ner.2015.7146816

Argelaguet, F., Hoyet, L., Trico, M., \& Lécuyer, A. (2016). The role of interaction in virtual embodiment: Effects of the virtual hand representation. Proceedings - IEEE Virtual Reality. https://doi.org/10.1109/VR.2016.7504682

Aspinall, P., Mavros, P., Coyne, R., \& Roe, J. (2015). The urban brain: Analysing outdoor physical activity with mobile EEG. British Journal of Sports Medicine. https://doi.org/10.1136/bjsports-2012091877

Banaei, M., Hatami, J., Yazdanfar, A., \& Gramann, K. (2017). Walking through Architectural Spaces: The Impact of Interior Forms on Human Brain Dynamics. Frontiers in Human Neuroscience, 11. doi:10.3389/fnhum.2017.00477

Bayliss, J. D., \& Ballard, D. H. (2000). A virtual reality testbed for brain-computer interface research. IEEE Transactions on Rehabilitation Engineering, 8(2), 188-190. doi:10.1109/86.847811

Bohr, I., \& Read, J. C. A. (2013). Stereoacuity with Frisby and Revised FD2 Stereo Tests. PLoS ONE, 8(12), e82999. doi:10.1371/journal.pone.0082999

Brown, C. R., Clarke, A. R., \& Barry, R. J. (2007). Auditory processing in an inter-modal oddball task: Effects of a combined auditory/visual standard on auditory target ERPs. International Journal of Psychophysiology. https://doi.org/10.1016/j.ijpsycho.2007.04.002

Campanella, S., Bruyer, R., Froidbise, S., Rossignol, M., Joassin, F., Kornreich, C., ... Verbanck, P. (2010). Is two better than one? A cross-modal oddball paradigm reveals greater sensitivity of the 
NOVEL ODDBALL PARADIGM IN VIRTUAL REALITY

613

614

615

616

617

618

619

620

621

622

623

624

625

626

627

628

629

630

631

632

633

634

635

636

637

638

P300 to emotional face-voice associations. Clinical Neurophysiology.

https://doi.org/10.1016/j.clinph.2010.04.004

Canzoneri, E., Ubaldi, S., Rastelli, V., Finisguerra, A., Bassolino, M., \& Serino, A. (2013). Tool-use reshapes the boundaries of body and peripersonal space representations. Experimental Brain Research, 228(1), 25-42. https://doi.org/10.1007/s00221-013-3532-2

Choi, Y.-H., Ku, J., Lim, H., Kim, Y. H., \& Paik, N.-J. (2016). Mobile game-based virtual reality rehabilitation program for upper limb dysfunction after ischemic stroke. Restorative Neurology and Neuroscience. https://doi.org/10.3233/RNN-150626

Dankert, T., Heil, D., Pfeiffer, T. (2013). Stereo vision and acuity tests within a virtual reality set-up. In M. E. Latoschik, O. Staadt, \& F. Steinicke (Eds.), Virtuelle und Erweiterte Realität - 10. Workshop der GI-Fachgruppe VR/AR (pp. 185-188). Shaker Verlag.

Debener, S., Minow, F., Emkes, R., Gandras, K., \& de Vos, M. (2012). How about taking a low-cost, small, and wireless EEG for a walk? Psychophysiology, 49(11), 1617-1621. doi:10.1111/j.14698986.2012.01471.x

de Vignemont, F., \& Iannetti, G. D. (2015). How many peripersonal spaces? Neuropsychologia, 70, 327334. https://doi.org/10.1016/J.NEUROPSYCHOLOGIA.2014.11.018

Delorme, A., \& Makeig, S. (2004). EEGLAB: an open source toolbox for analysis of single-trial EEG dynamics including independent component analysis. Journal of Neuroscience Methods, 134(1), 921. https://doi.org/10.1016/J.JNEUMETH.2003.10.009

di Pellegrino, G., \& Làdavas, E. (2015). Peripersonal space in the brain. Neuropsychologia, 66, 126-133. https://doi.org/10.1016/j.neuropsychologia.2014.11.011

Fonteneau, E., \& Davidoff, J. (2007). Neural correlates of colour categories. NeuroReport. https://doi.org/10.1097/WNR.0b013e3282c48c33

Goncharova, I. I., McFarland, D. J., Vaughan, T. M., \& Wolpaw, J. R. (2003). EMG contamination of EEG: spectral and topographical characteristics. Clinical neurophysiology, 114(9), 1580-1593. https://doi.org/10.1016/S1388-2457(03)00093-2 
NOVEL ODDBALL PARADIGM IN VIRTUAL REALITY

639

640

641

642

643

644

645

646

647

648

649

650

651

652

653

654

655

656

657

658

659

660

661

662

663

Gratton, G., Coles, M. G. ., \& Donchin, E. (1983). A new method for off-line removal of ocular artifact. Electroencephalography and Clinical Neurophysiology, 55(4), 468-484. https://doi.org/10.1016/0013-4694(83)90135-9

Hagemann, D., \& Naumann, E. (2001). The effects of ocular artifacts on (lateralized) broadband power in the EEG. Clinical Neurophysiology, 112(2), 215-231. https://doi.org/10.1016/S1388-2457(00)005411

Harjunen, V. J., Ahmed, I., Jacucci, G., Ravaja, N., \& Spapé, M. M. (2017). Manipulating Bodily Presence Affects Cross-Modal Spatial Attention: A Virtual-Reality-Based ERP Study. Frontiers in Human Neuroscience, 11. doi:10.3389/fnhum.2017.00079

Henderson, M., Vo, V., Chunharas, C., Sprague, T., Serences, J. (2019). Multivariate analysis of BOLD activation patterns recovers graded depth representations in human visual and parietal cortex. eNeuro, 6(4), 1-15. https://doi.org/10.1523/ENEURO.0362-18.2019

Hentschke, H., \& Stüttgen, M. C. (2011). Computation of measures of effect size for neuroscience data sets. European Journal of Neuroscience, 34(12), 1887-1894. https://doi.org/10.1111/j.14609568.2011.07902.x

Ho, T.-H., Yang, F.-C., Lin, R.-C., Chien, W.-C., Chung, C.-H., Chiang, S.-L., ... Lee, J.-T. (2019). Impact of virtual reality-based rehabilitation on functional outcomes in patients with acute stroke: a retrospective case-matched study. Journal of Neurology, 266(3), 589-597. https://doi.org/10.1007/s00415-018-09171-2

Jarosz, A. F., \& Wiley, J. (2014). What Are the Odds? A Practical Guide to Computing and Reporting Bayes Factors. The Journal of Problem Solving, 7(1). https://doi.org/10.7771/1932-6246.1167

JASP Team (2019). JASP (Version 0.10.2)[Computer software].

Kuziek, J. W. P., Shienh, A., \& Mathewson, K. E. (2017). Transitioning EEG experiments away from the laboratory using a Raspberry Pi 2. Journal of Neuroscience Methods. https://doi.org/10.1016/j.jneumeth.2016.11.013 
NOVEL ODDBALL PARADIGM IN VIRTUAL REALITY

664

Làdavas, E. (2002). Functional and dynamic properties of visual peripersonal space. Trends in Cognitive Sciences, 6(1), 17-22. https://doi.org/10.1016/S1364-6613(00)01814-3

Laszlo, S., Ruiz-Blondet, M., Khalifian, N., Chu, F., \& Jin, Z. (2014). A direct comparison of active and passive amplification electrodes in the same amplifier system. Journal of Neuroscience Methods. https://doi.org/10.1016/j.jneumeth.2014.05.012

Lee, J. H., Ku, J., Kim, K., Kim, B., Kim, I. Y., Yang, B.-H., ... Kim, S. I. (2003). Experimental Application of Virtual Reality for Nicotine Craving through Cue Exposure. CyberPsychology \& Behavior. https://doi.org/10.1089/109493103322011560

Liu, B., Meng, X., Wu, G., \& Dang, J. (2013). Correlation between three-dimensional visual depth and N2 component: Evidence from event-related potential study. Neuroscience, 237, 161-169. doi:10.1016/j.neuroscience.2013.01.045

Mathewson, K. E., Harrison, T. J. L., \& Kizuk, S. A. D. (2017). High and dry? Comparing active dry EEG electrodes to active and passive wet electrodes. Psychophysiology, 54(1), 74-82. https://doi.org/10.1111/psyp.12536

Mathewson, K. E., Lleras, A., Beck, D. M., Fabiani, M., Ro, T., \& Gratton, G. (2011). Pulsed Out of Awareness: EEG Alpha Oscillations Represent a Pulsed-Inhibition of Ongoing Cortical Processing. Frontiers in Psychology, 2, 99. https://doi.org/10.3389/fpsyg.2011.00099

Naceri, A., Moscatelli, A., \& Chellali, R. (2015). Depth discrimination of constant angular size stimuli in action space: Role of accommodation and convergence cues. Frontiers in Human Neuroscience, 9. doi:10.3389/fnhum.2015.00511

Pugnetti, L., Mendozzi, L., Attree, E. A., Sc, B., Barbieri, E., Ph, D., ... Psychol, C. (1998). Probing Memory and Executive Functions with Virtual Reality: Past and Present Studies. CyberPsychology. Raz, S., Dan, O., \& Zysberg, L. (2014). Neural correlates of emotional intelligence in a visual emotional oddball task: An ERP study. Brain and Cognition. https://doi.org/10.1016/j.bandc.2014.09.003

Robinson, C., Ahmar, N., Sloutsky, V., Robinson, C. W., \& Sloutsky, V. M. (n.d.). UC Merced Proceedings of the Annual Meeting of the Cognitive Science Society Title Evidence for auditory 
NOVEL ODDBALL PARADIGM IN VIRTUAL REALITY

dominance in a passive oddball task Publication Date Evidence for auditory dominance in a passive oddball task. (32), 32. Retrieved from https://escholarship.org/dist/wJD5zTgC2vrImRR/dist/prd/content/qt9gg173d6/qt9gg173d6.pdf

Rothbaum, B. O., Price, M., Jovanovic, T., Norrholm, S. D., Gerardi, M., Dunlop, B., ... Ressler, K. J. (2014). A randomized, double-blind evaluation of D-cycloserine or alprazolam combined with virtual reality exposure therapy for posttraumatic stress disorder in Iraq and Afghanistan war veterans. American Journal of Psychiatry. https://doi.org/10.1176/appi.ajp.2014.13121625

Safir, M. P., Wallach, H. S., \& Bar-Zvi, M. (2012). Virtual Reality Cognitive-Behavior Therapy for Public Speaking Anxiety. Behavior Modification, 36(2), 235-246. https://doi.org/10.1177/0145445511429999

Sawaragi, T., \& Horiguchi, Y. (n.d.). Analysis of task morphologies for networking behavioral skills via virtual reality. Proceedings. IEEE 8th International Workshops on Enabling Technologies: Infrastructure for Collaborative Enterprises (WET ICE'99), 200-207. https://doi.org/10.1109/ENABL.1999.805202 Taking off the training wheels: Measuring auditory P3 during outdoor cycling using an active wet EEG system. Brain Research. https://doi.org/10.1016/j.brainres.2017.12.010

Smith, M. J., Boteler Humm, L., Fleming, M. F., Jordan, N., Wright, M. A., Ginger, E J., ... Bell, M. D. (2015). Virtual reality job interview training for veterans with posttraumatic stress disorder. Journal of Vocational Rehabilitation. https://doi.org/10.3233/JVR-150748

Strickland, D., \& Chartier, D. (1997). EEG Measurements in a Virtual Reality Headset. Presence: Teleoperators and Virtual Environments, 6(5), 581-589. doi:10.1162/pres.1997.6.5.581

712 Wagenmakers, E.-J., Love, J., Marsman, M., Jamil, T., Ly, A., Verhagen, J., ... Morey, R. D. (2018).

713 Bayesian inference for psychology. Part II: Example applications with JASP. Psychonomic Bulletin 714 \& Review, 25(1), 58-76. https://doi.org/10.3758/s13423-017-1323-7 
NOVEL ODDBALL PARADIGM IN VIRTUAL REALITY

715 Wagenmakers, E.-J., Marsman, M., Jamil, T., Ly, A., Verhagen, J., Love, J., ... Morey, R. D. (2018).

Bayesian inference for psychology. Part I: Theoretical advantages and practical ramifications.

VIVE Virtual Reality System. (2011). Retrieved from https://www.vive.com/us/product/vive-virtualreality-system/

Zink, R., Hunyadi, B., Huffel, S. Van, \& Vos, M. De. (2016). Mobile EEG on the bike: Disentangling attentional and physical contributions to auditory attention tasks. Journal of Neural Engineering. 
NOVEL ODDBALL PARADIGM IN VIRTUAL REALITY

739 Acknowledgements

740 This work was supported by a discovery grant to KEM from the Natural Sciences and Engineering

741 Research Council (NSERC) of Canada and start-up funds from the Faculty of Science. Thank you to all

742 members and volunteers of the Mathewson lab for assisting with data collection and experimental setup.

743 Thank you to our collaborators at IBM Research for providing help and guidance designing the virtual

744 reality task and environment.

745

746

747

748

749

750

751

752

753

754

755

756

757

758

759

760

761

762 
763 Tables

\begin{tabular}{ccccccc}
\hline Condition & $\begin{array}{c}\text { Oddball } \\
\text { Task }\end{array}$ & $\begin{array}{c}\text { Stimulus } \\
\text { Type }\end{array}$ & $\begin{array}{c}\text { Mean } \\
\text { Trial } \\
\text { Count }\end{array}$ & $\begin{array}{c}\text { Standard } \\
\text { Deviation }\end{array}$ & $\begin{array}{c}\text { Trial } \\
\text { Count } \\
\text { Range }\end{array}$ & $\begin{array}{c}\text { Minimum } \\
\text { Trials Remaining } \\
(\%)\end{array}$ \\
\hline Non-VR & Auditory & Target & 50.63 & 7.48 & $37-70$ & 94.12 \\
Non-VR & Auditory & Standard & 197.04 & 7.78 & $180-213$ & 94.47 \\
VR & Auditory & Target & 49.71 & 6.07 & $37-61$ & 94.12 \\
VR & Auditory & Standard & 198.33 & 6.88 & $187-213$ & 94.47 \\
Non-VR & Visual & Target & 50.71 & 5.07 & $43-60$ & 95.65 \\
Non-VR & Visual & Standard & 197.13 & 6.36 & $182-206$ & 91.46 \\
VR & Visual & Target & 49.38 & 4.98 & $39-60$ & 97.92 \\
VR & Visual & Standard & 199.92 & 4.90 & $190-208$ & 97.01 \\
\hline
\end{tabular}

764 Table 1: Trial count information for both target and standard trials across condition (Non-VR; VR) and

765 oddball modality (Auditory; Visual).

766

767

768

769

770

771

772

773

774

775

776

777

778

779

780

781 
$782 \quad \mathbf{A}$

\begin{tabular}{|c|c|c|c|c|c|c|c|c|c|}
\hline Condition & $\begin{array}{c}\text { Oddball } \\
\text { Task }\end{array}$ & $\begin{array}{l}\text { Electrode/ } \\
\text { Time } \\
\text { Window }\end{array}$ & $\begin{array}{c}\text { Mean } \\
\text { Voltage } \\
(\mu \mathrm{V})\end{array}$ & $\begin{array}{c}\text { Standard } \\
\text { Deviation } \\
(\mu \mathrm{V})\end{array}$ & $t(23)$ & $p$ & $\begin{array}{l}\text { Confidence } \\
\text { Interval }\end{array}$ & Hedge's $g$ & $\mathbf{B F}_{10}$ \\
\hline Non-VR & Auditory & Fz/N2 & -2.98 & 2.71 & -5.40 & $<0.01$ & -Inf:-2.03 & -1.07 & $1.30 \mathrm{e} 3$ \\
\hline Non-VR & Auditory & $\mathrm{Pz} / \mathrm{P} 3$ & 5.50 & 4.20 & 6.42 & $<0.01$ & 4.04:Inf & 1.27 & $1.24 \mathrm{e} 4$ \\
\hline VR & Auditory & $\mathrm{Fz} / \mathrm{N} 2$ & -1.88 & 2.77 & -3.32 & $<0.01$ & -Inf:-0.91 & -0.66 & 13.52 \\
\hline VR & Auditory & Pz/P3 & 6.06 & 5.08 & 5.84 & $<0.01$ & 4.28:Inf & 1.15 & $3.51 \mathrm{e} 3$ \\
\hline Non-VR & Visual & $\mathrm{Fz} / \mathrm{N} 2$ & -0.03 & 1.53 & -0.10 & 0.46 & -Inf:0.50 & -0.02 & 0.22 \\
\hline Non-VR & Visual & Pz/P3 & 6.58 & 3.77 & 8.55 & $<0.01$ & 5.26:Inf & 1.69 & $9.72 \mathrm{e} 5$ \\
\hline VR & Visual & Fz/N2 & 0.33 & 1.94 & 0.83 & 0.79 & -Inf:1.01 & 0.16 & 0.30 \\
\hline VR & Visual & $\mathrm{Pz} / \mathrm{P} 3$ & 6.00 & 3.72 & 7.89 & $<0.01$ & 4.70:Inf & 1.56 & $2.65 \mathrm{e} 5$ \\
\hline
\end{tabular}

783

784 B

\begin{tabular}{ccccccccc}
\hline Oddball Task & $\begin{array}{c}\text { Electrode/ } \\
\text { Time } \\
\text { Window }\end{array}$ & $\begin{array}{c}\text { Mean } \\
\text { Voltage } \\
(\boldsymbol{\mu} \mathbf{V})\end{array}$ & $\begin{array}{c}\text { Standard } \\
\text { Deviation } \\
(\boldsymbol{\mu} \mathbf{V})\end{array}$ & $\boldsymbol{t}(\mathbf{2 3})$ & $\boldsymbol{p}$ & $\begin{array}{c}\text { Confidence } \\
\text { Interval }\end{array}$ & Hedge's $\boldsymbol{g}^{\text {BF }_{10}}$ \\
\hline Auditory & Fz/N2 & -1.10 & 3.35 & -1.40 & 0.17 & $-2.70: 0.49$ & -0.39 & 0.67 \\
Auditory & $\mathrm{Pz} / \mathrm{P} 3$ & -0.55 & 2.50 & -0.41 & 0.68 & $-3.26: 2.16$ & -0.12 & 0.36 \\
Visual & Fz/N2 & -0.36 & 2.33 & -0.71 & 0.48 & $-1.37:-0.71$ & -0.20 & 0.28 \\
Visual & Pz/P3 & 0.59 & 2.66 & 0.54 & 0.59 & $-1.59: 2.77$ & 0.15 & 0.36 \\
\hline
\end{tabular}

785 Table 2: Results of one-tailed and two-tailed $t$-tests, Bayesian one-tailed and two-tailed $t$-tests, and

786 estimated measures of effect size on the ERP difference waves. A) One tailed $t$-test and Bayes Factor

787 results to determine if a significant N2 and P3 response was observed for each condition and oddball task.

788 Bayes factors were calculated by testing if the N2/P3 waveforms for each condition/oddball task were less

789 than or greater than zero, respectively. Hedge's $g$ is used to estimate effect size. B) Two-tailed $t$-test and

790 Bayes paired-t-test results comparing the N2 and P3 waveforms for each condition and oddball task.

791 Bayes Factors $\left(\mathrm{BF}_{10}\right)$ were calculated by comparing the N2 and $\mathrm{P} 3$ waveforms between Non-VR and VR

792 conditions.

793

794

795

796

797

798

799

800 
NOVEL ODDBALL PARADIGM IN VIRTUAL REALITY

$\begin{array}{ccccr}\text { Stimulus Type } & \text { Mean Trial Count } & \begin{array}{c}\text { Standard } \\ \text { Deviation }\end{array} & \begin{array}{c}\text { Trial Count Range } \\ \text { (Minimum:Maximum) }\end{array} & \begin{array}{c}\text { Minimum } \\ \text { Trials Remain }\end{array} \\ \text { Far Targets } & 94.44 & 9.72 & 80: 112 & 72.10 \\ \text { Near Standards } & 394.72 & 38.73 & 244: 416 & 62.72 \\ \text { Near Targets } & 100.33 & 7.51 & 87: 113 & 96.67 \\ \text { Far Standards } & 397.06 & 8.39 & 377: 412 & 95.93\end{array}$

801 Table 3: Trial count information for both target and standard trials across both the Far and Near 802 conditions.

803

804

805

806

807

808

809

810

811

812

813

814

815

816

817

818

819

820 
NOVEL ODDBALL PARADIGM IN VIRTUAL REALITY

\begin{tabular}{ccccccccc}
\hline Condition & $\begin{array}{c}\text { Electrode/ } \\
\text { Time Window }\end{array}$ & $\begin{array}{c}\text { Mean } \\
\text { Voltage } \\
(\boldsymbol{\mu} \mathbf{V})\end{array}$ & $\begin{array}{c}\text { Standard } \\
\text { Deviation } \\
(\boldsymbol{\mu V})\end{array}$ & $\boldsymbol{t}(\mathbf{1 7})$ & $\boldsymbol{p}$ & $\begin{array}{c}\text { Confidence } \\
\text { Interval }\end{array}$ & Hedge's $\boldsymbol{g}^{\text {BF }} \mathbf{1 0}$ \\
\hline $\mathbf{A}$ & $\mathrm{Pz} / 175-225 \mathrm{~ms}$ & -1.17 & 2.07 & -2.40 & 0.014 & - Inf:-0.32 & -0.54 & 2.28 \\
$\mathbf{A}$ & $\mathrm{Pz} / 225-300 \mathrm{~ms}$ & 1.15 & 1.93 & 2.52 & 0.011 & $0.35:$ Inf & 0.57 & 2.77 \\
$\mathbf{A}$ & $\mathrm{Pz} / 349-623 \mathrm{~ms}$ & -0.18 & 1.29 & -0.61 & 0.28 & - Inf: 0.35 & -0.14 & 0.29 \\
$\mathbf{B}$ & $\mathrm{Pz} / 175-225 \mathrm{~ms}$ & 2.70 & 2.52 & 4.54 & $<0.01$ & $1.67:$ Inf & 1.02 & 111.00 \\
$\mathbf{B}$ & $\mathrm{Pz} / 225-300 \mathrm{~ms}$ & -1.44 & 2.91 & -2.10 & 0.25 & - Inf:-0.25 & -0.47 & 1.43 \\
$\mathbf{B}$ & $\mathrm{Pz} / 349-623 \mathrm{~ms}$ & -0.53 & 3.25 & -0.70 & 0.25 & - Inf:0.80 & -0.16 & 0.30 \\
\hline
\end{tabular}

821 A = Far Standards - Near Standards; B = Far Targets - Near Targets

822

\begin{tabular}{ccccccccc}
\hline Condition & $\begin{array}{c}\text { Electrode/ } \\
\text { Time Window }\end{array}$ & $\begin{array}{c}\text { Mean } \\
\text { Voltage } \\
(\boldsymbol{\mu} \mathbf{V})\end{array}$ & $\begin{array}{c}\text { Standard } \\
\text { Deviation } \\
(\boldsymbol{\mu} \mathbf{V})\end{array}$ & $\boldsymbol{t}(\mathbf{1 8})$ & $\boldsymbol{p}$ & $\begin{array}{c}\text { Confidence } \\
\text { Interval }\end{array}$ & Hedge's $\boldsymbol{g}$ & BF $_{10}$ \\
\hline $\mathbf{C}$ & $\mathrm{Pz} / 175-225 \mathrm{~ms}$ & 1.37 & 2.26 & 2.57 & $<0.01$ & $0.44:$ Inf & 0.58 & 3.02 \\
$\mathbf{C}$ & $\mathrm{Pz} / 225-300 \mathrm{~ms}$ & -0.62 & 3.29 & -0.79 & 0.22 & - Inf:0.73 & -0.18 & 0.32 \\
$\mathbf{C}$ & $\mathrm{Pz} / 349-623 \mathrm{~ms}$ & 5.77 & 3.11 & 7.88 & $<0.01$ & $4.50:$ Inf & 1.77 & $3.73 \mathrm{e}+4$ \\
$\mathbf{D}$ & $\mathrm{Pz} / 175-225 \mathrm{~ms}$ & -2.51 & 1.94 & -5.49 & $<0.01$ & - Inf:- 1.71 & -1.24 & 641.08 \\
$\mathbf{D}$ & $\mathrm{Pz} / 225-300 \mathrm{~ms}$ & 1.97 & 2.68 & 3.12 & $<0.01$ & $0.87:$ Inf & 0.70 & 7.87 \\
$\mathbf{D}$ & $\mathrm{Pz} / 349-623 \mathrm{~ms}$ & 6.12 & 2.48 & 10.47 & $<0.01$ & $5.10:$ :nf & 2.36 & $1.52 \mathrm{e}+6$ \\
\hline
\end{tabular}

\section{C = Far Condition Targets - Standards; $\mathbf{D}=$ Near Condition Targets - Standards}

824 Table 4: Results of one-tailed $t$-tests, Bayesian one-tailed $t$-tests, and estimated measures of effect size 825 for the ERP waveforms at three time windows. Hedge's $g$ is used to estimate effect size. Bayes factors 826 were calculated by testing if the waveforms at each time window was less or greater than zero, based on 827 the mean voltage. $\mathrm{BF}_{10}$ indicates support for $\mathrm{H} 1$ over $\mathrm{H} 0$.

828

829

830

831

832

833

834

835 
NOVEL ODDBALL PARADIGM IN VIRTUAL REALITY

\begin{tabular}{|c|c|c|c|c|c|c|c|c|}
\hline $\begin{array}{c}\text { Oddball } \\
\text { Tasks } \\
\text { Compared }\end{array}$ & $\begin{array}{c}\text { Electrode/ } \\
\text { Time Window }\end{array}$ & $\begin{array}{c}\text { Mean } \\
\text { Voltage } \\
(\mu \mathrm{V})\end{array}$ & $\begin{array}{c}\text { Standard } \\
\text { Deviation } \\
(\mu \mathrm{V})\end{array}$ & $t(17)$ & $p$ & $\begin{array}{l}\text { Confidence } \\
\text { Interval }\end{array}$ & Hedge's $g$ & $\mathrm{BF}_{10}$ \\
\hline C:D & $\mathrm{Pz} / 175-225 \mathrm{~ms}$ & 3.88 & 3.68 & 4.47 & $<0.01$ & $2.05: 5.70$ & 1.80 & 97.33 \\
\hline$C: D$ & $\mathrm{Pz} / 225-300 \mathrm{~ms}$ & -2.59 & 4.03 & -2.72 & 0.014 & $-4.59:-0.58$ & -0.84 & 3.91 \\
\hline C:D & $\mathrm{Pz} / 349-623 \mathrm{~ms}$ & -0.35 & 3.44 & -0.43 & 0.67 & $-2.06: 1.36$ & -0.12 & 0.26 \\
\hline
\end{tabular}

837 C = Far Condition Targets - Standards $;$ D = Near Condition Targets - Standards

838 Table 5: Results of two-tailed $t$-tests, Bayesian paired $t$-tests, and estimates of measure of effect size 839 between the ERP waveforms at three time windows for electrode Pz. Hedge's $g$ is used to estimate effect 840 size. Bayes factors were calculated by comparing both waveforms at each time window. $\mathrm{BF}_{10}$ indicates 841 support for H1 over H0.

842

843

844

845

846

847

848

849

850

851

852

853

854

855

856 
859 Figure 1. Design of the experiments used for the A) auditory oddball and the B) visual oddball tasks. C) Response times (ms) following targets during the auditory and visual oddball tasks.

Figure 2: Grand-averaged ERP plots for target and standard stimuli at electrode Fz and Pz. Also shown are the difference waveforms for the A) auditory oddball and B) visual oddball tasks at electrode Fz and Pz. Difference waveforms were generated by subtracting the ERPs following standard stimuli from the ERPs following target stimuli. Yellow shaded regions represent the N2 and P3 time windows used for analyses. Topographies represent activity across the scalp while the bar graphs show activity at either electrode Fz or Pz, averaged across the N2 and P3 time windows. Error bars represent the standard error of the mean.

Figure 3: Spectra and RMS analysis for the auditory and visual oddball tasks. A) Grand-averaged spectra, topographies, and B) single-trial and grand-averaged RMS distributions for the auditory oddball task. Error bars in the spectra plots represent the standard deviation at each frequency. C) Grand-averaged spectra, topographies, and D) single-trial and grand-averaged RMS distributions for the oddball task.

872 Error bars on the mean RMS plots represent the standard deviation of the respective RMS distribution.

873 Figure 4: Plots showing the trials counts needed to obtain a significant N2 or P3 with $80 \%$ power for the A) auditory oddball and B) visual oddball tasks. Analyses were run using electrode Fz for the N2 waveform and electrode Pz for the P3 waveform.

Figure 5: Design and setup of the depth oddball task. A) Task setup for each participant and the location of the near and far orbs with respect to the participant. B) Virtual environment and appearance of the near and far stimuli from the perspective of the participant. C) Response times for target stimuli at both near and far depths. Error bars represent the standard error of the mean.

Figure 6: A) Grand-averaged ERP plots for target and standard stimuli at electrode Fz and Pz. B) Difference waveforms for near and far targets and standards. These waveforms were created by subtracting near standards from far standards, and near targets from far targets, at electrodes Fz and Pz. C) Difference waveforms for the Far Targets and Near Targets conditions. Plots were generated by subtracting ERPs to standards from the ERPs to targets in each condition. Far Targets Difference Wave = Far Condition Targets - Standards; Near Targets Difference Waveform $=$ Near Condition Targets Standards. Coloured shaded regions in each difference waveform represent the three time windows used for analyses. These windows are based on two opposing patterns of activity, and the P3 waveform, observed in the Far Targets and Near Targets difference waveforms at electrode Pz. Yellow $=175-225$ $\mathrm{ms}$; Orange $=225-300 \mathrm{~ms}$; Red $=349-623 \mathrm{~ms}$. Topographies represent activity across the scalp while bar graphs represent activity at either electrode $\mathrm{Fz}$ or $\mathrm{Pz}$, averaged across these time windows. All error bars in each plot represent the standard error of the mean.

Figure 7: Grand-averaged waveforms following targets and standards in the Near and Far conditions for 


\section{Figures}

A

A Non-VR

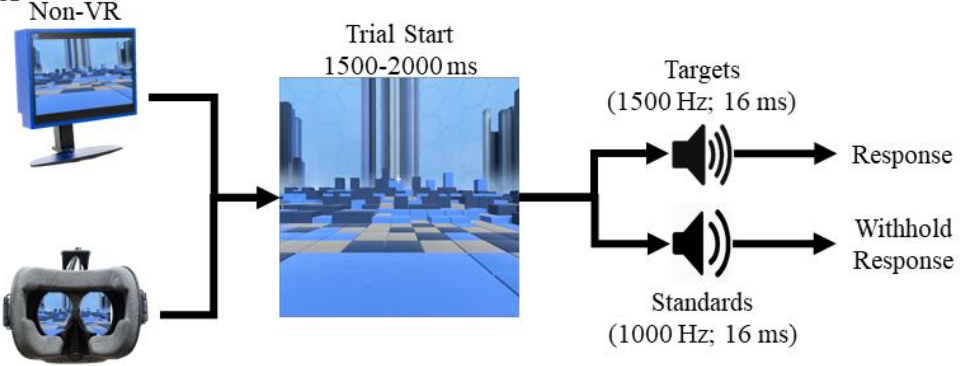

VR

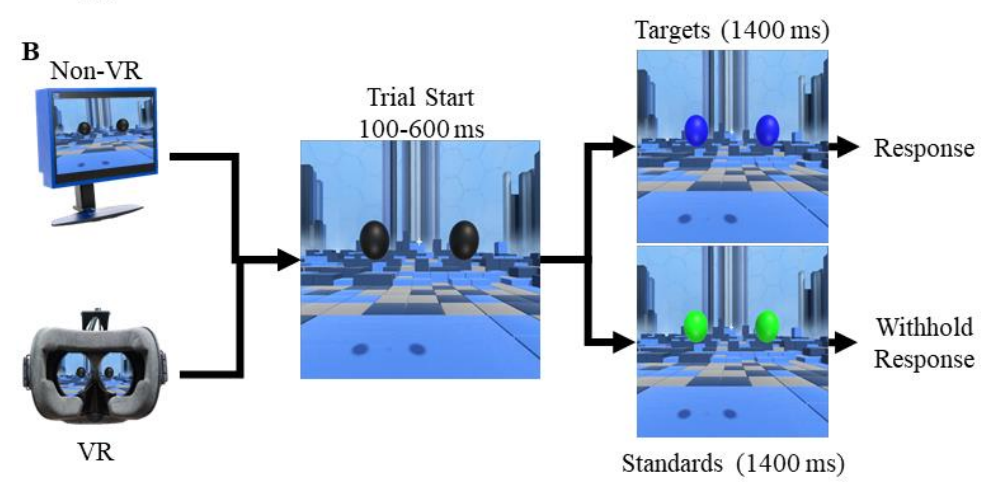

C

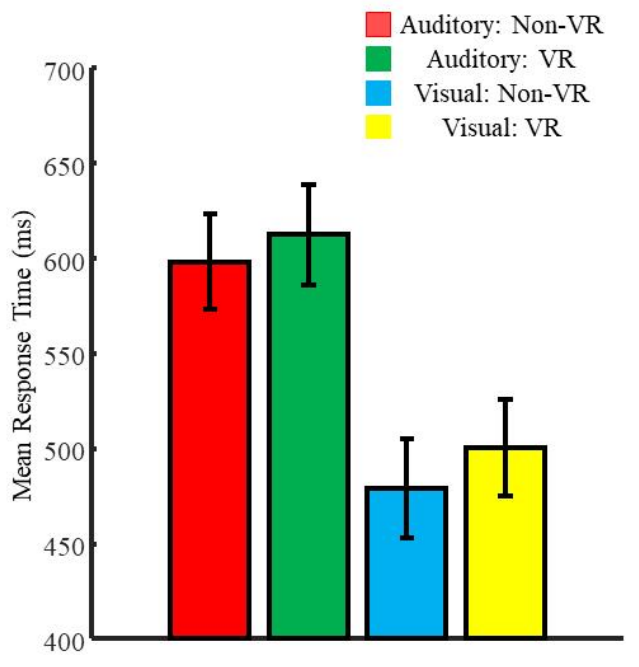

904

905

906

907

908

909

910

911

912 

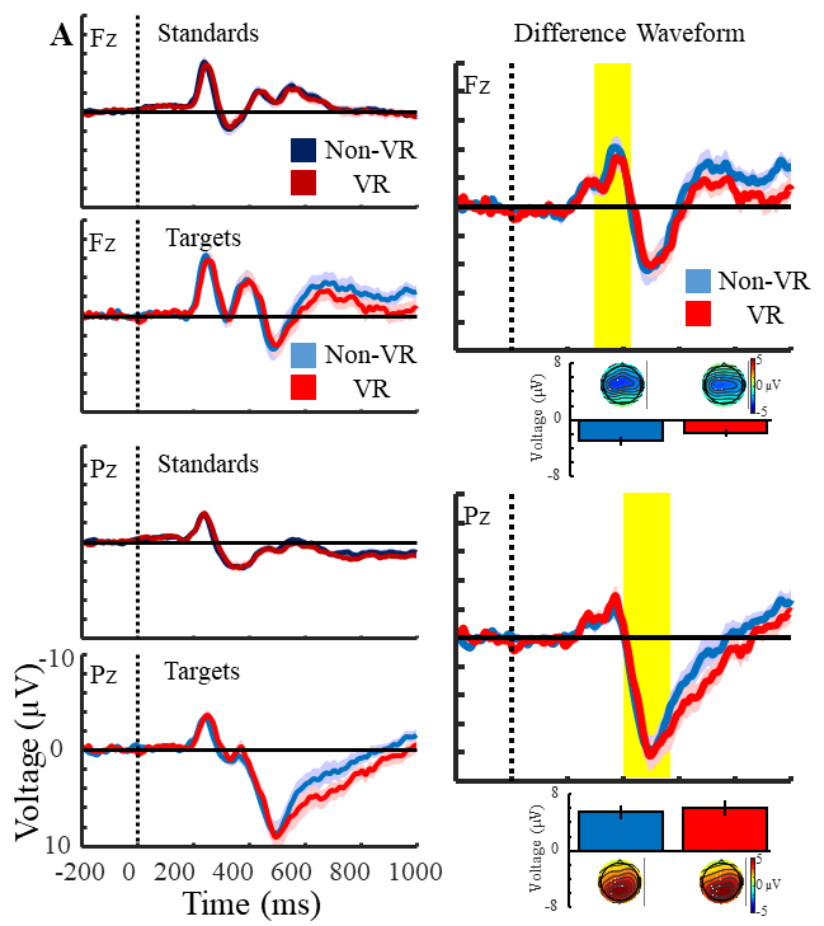

Difference Waveform
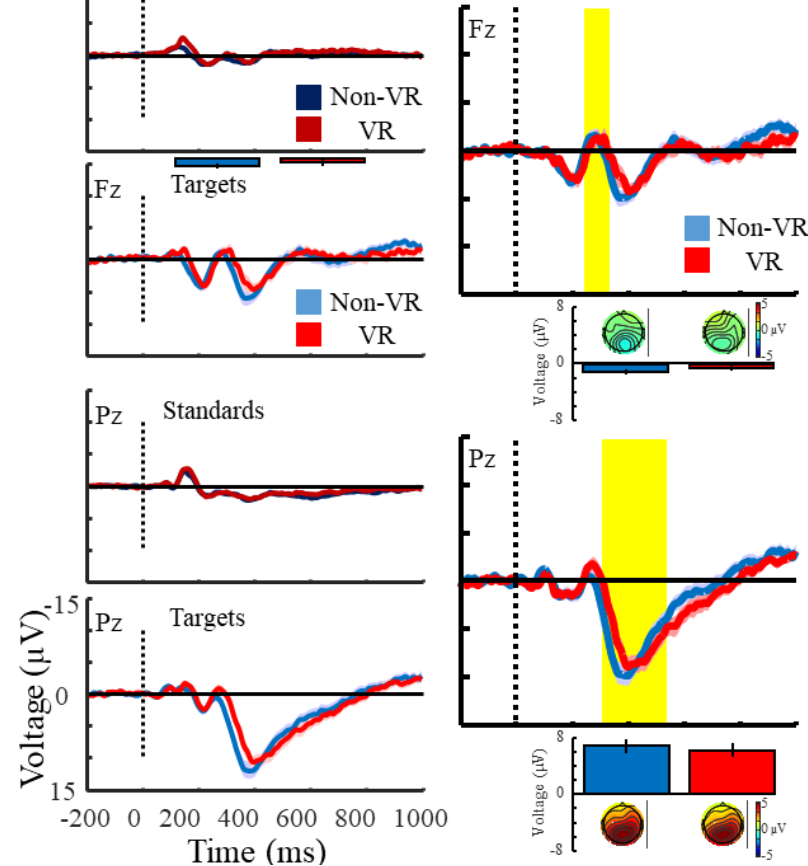

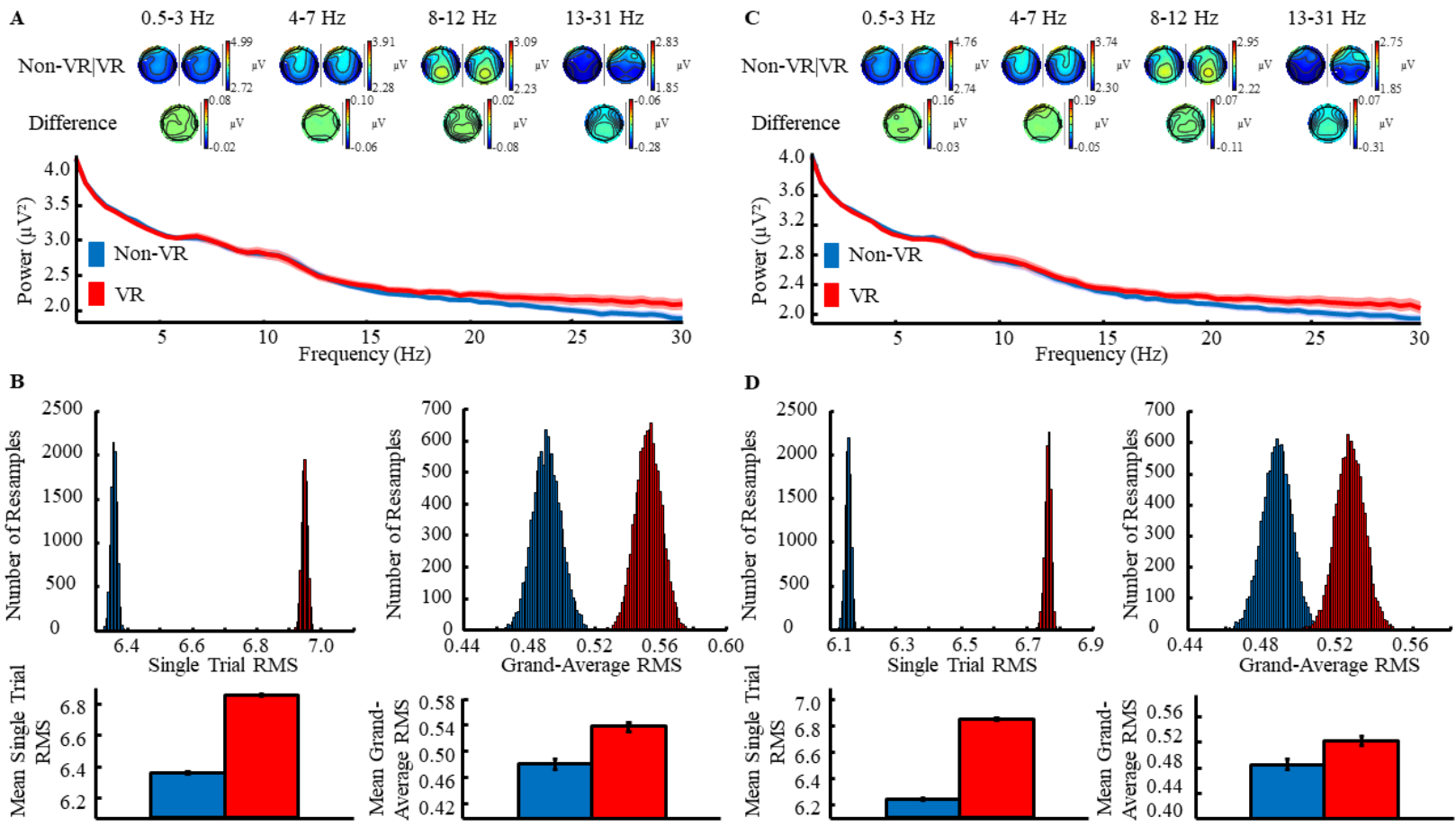
A
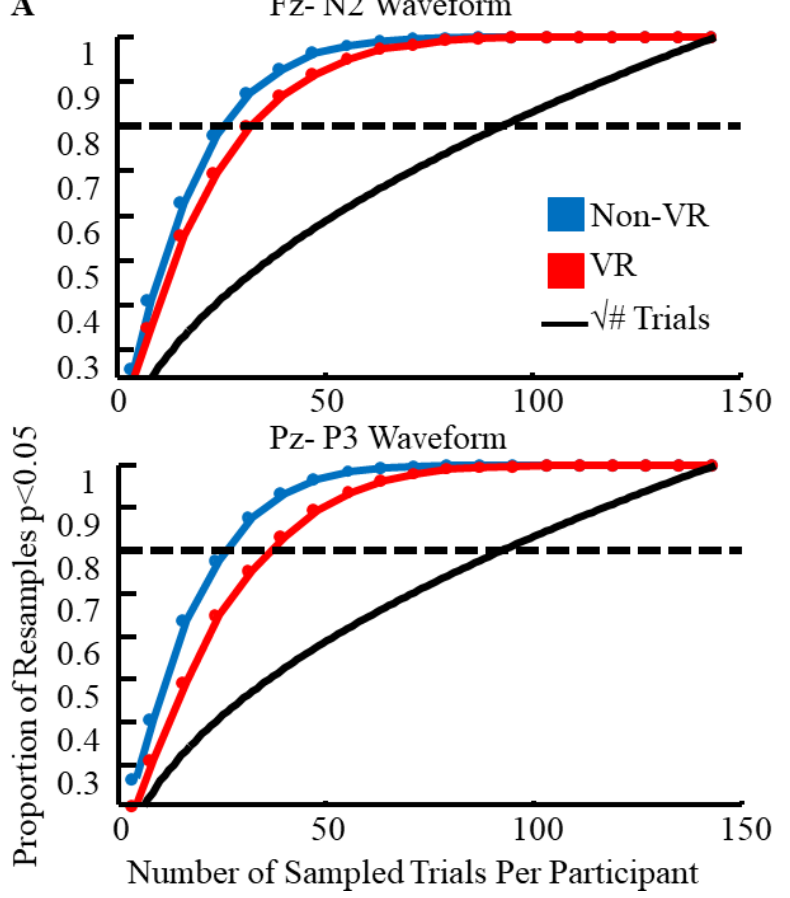

B
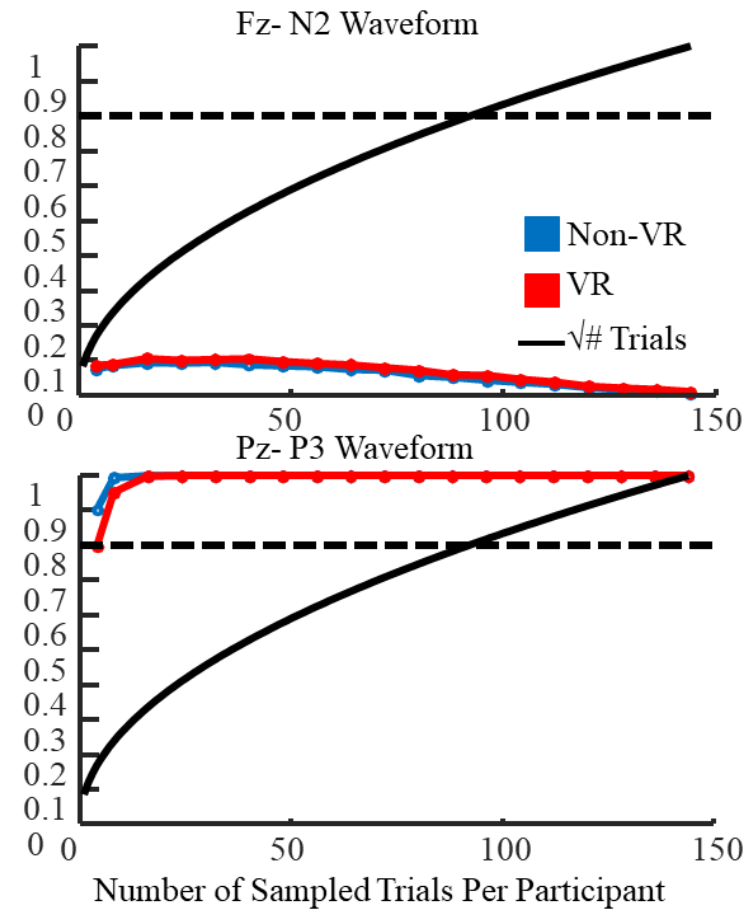

935

936

937

938

939

940

941 
NOVEL ODDBALL PARADIGM IN VIRTUAL REALITY

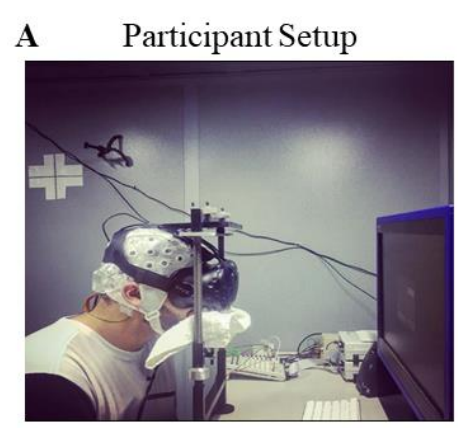

A Participant Setup

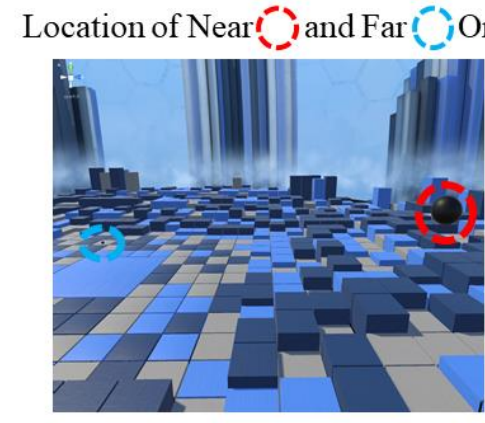

Fixation

B

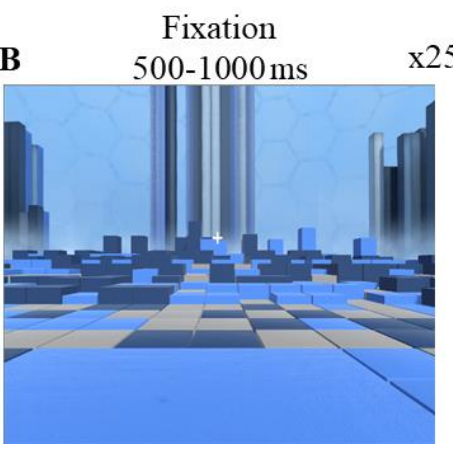

Near or Far Orb Onset

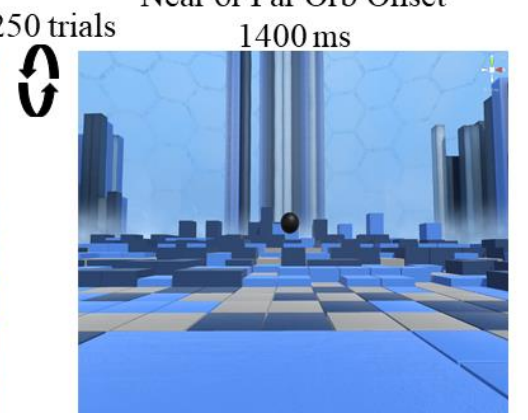

C

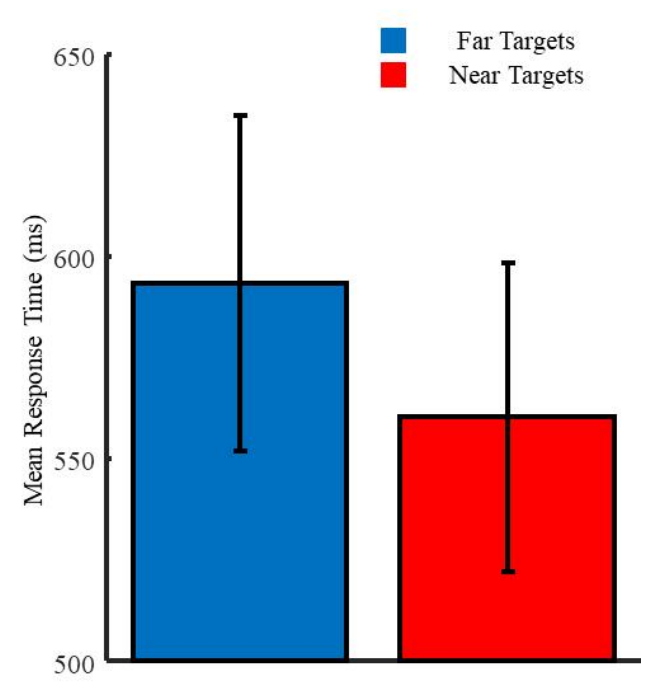



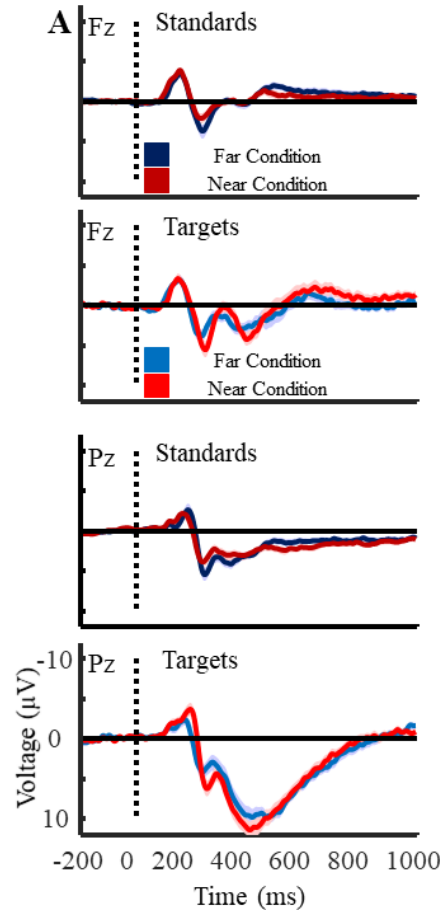

964

965

966

967

968

969

970

971

972
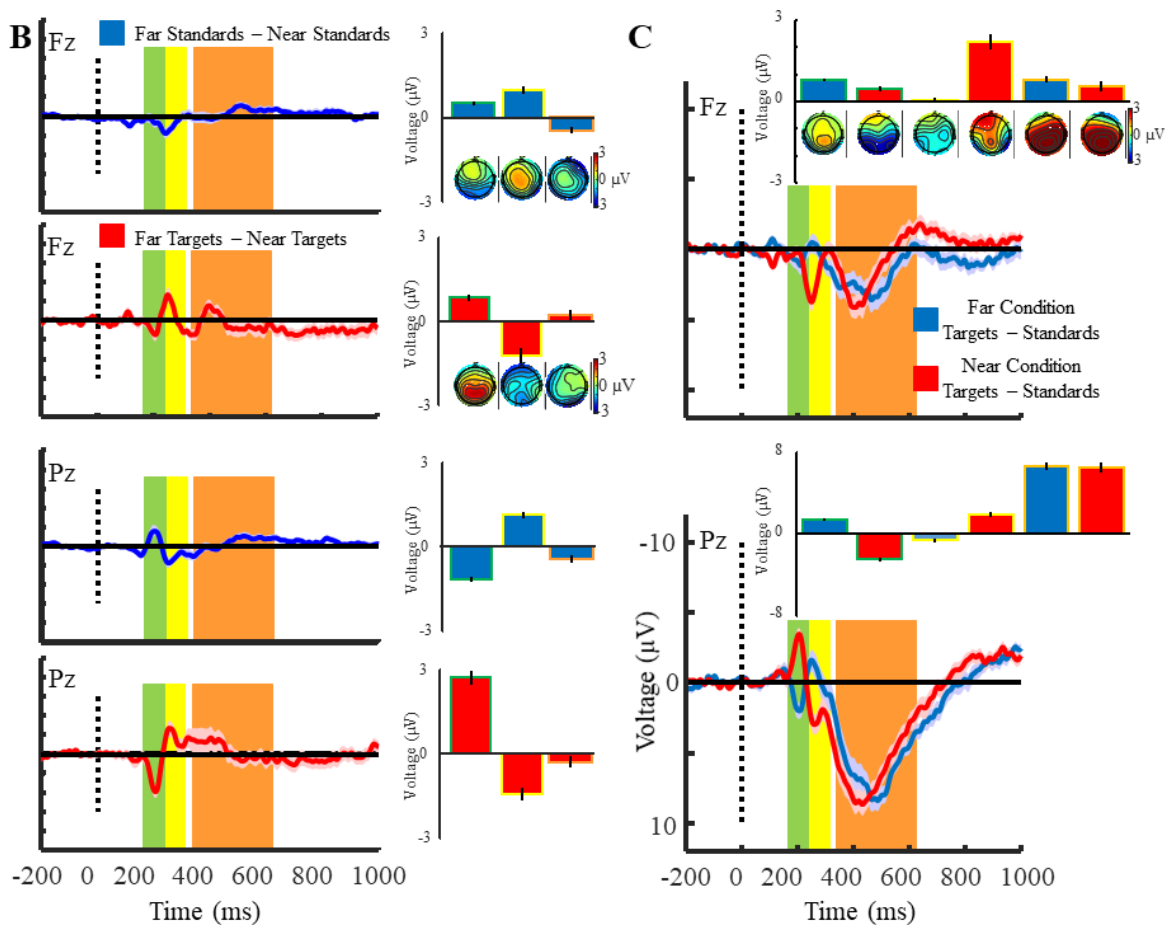
NOVEL ODDBALL PARADIGM IN VIRTUAL REALITY
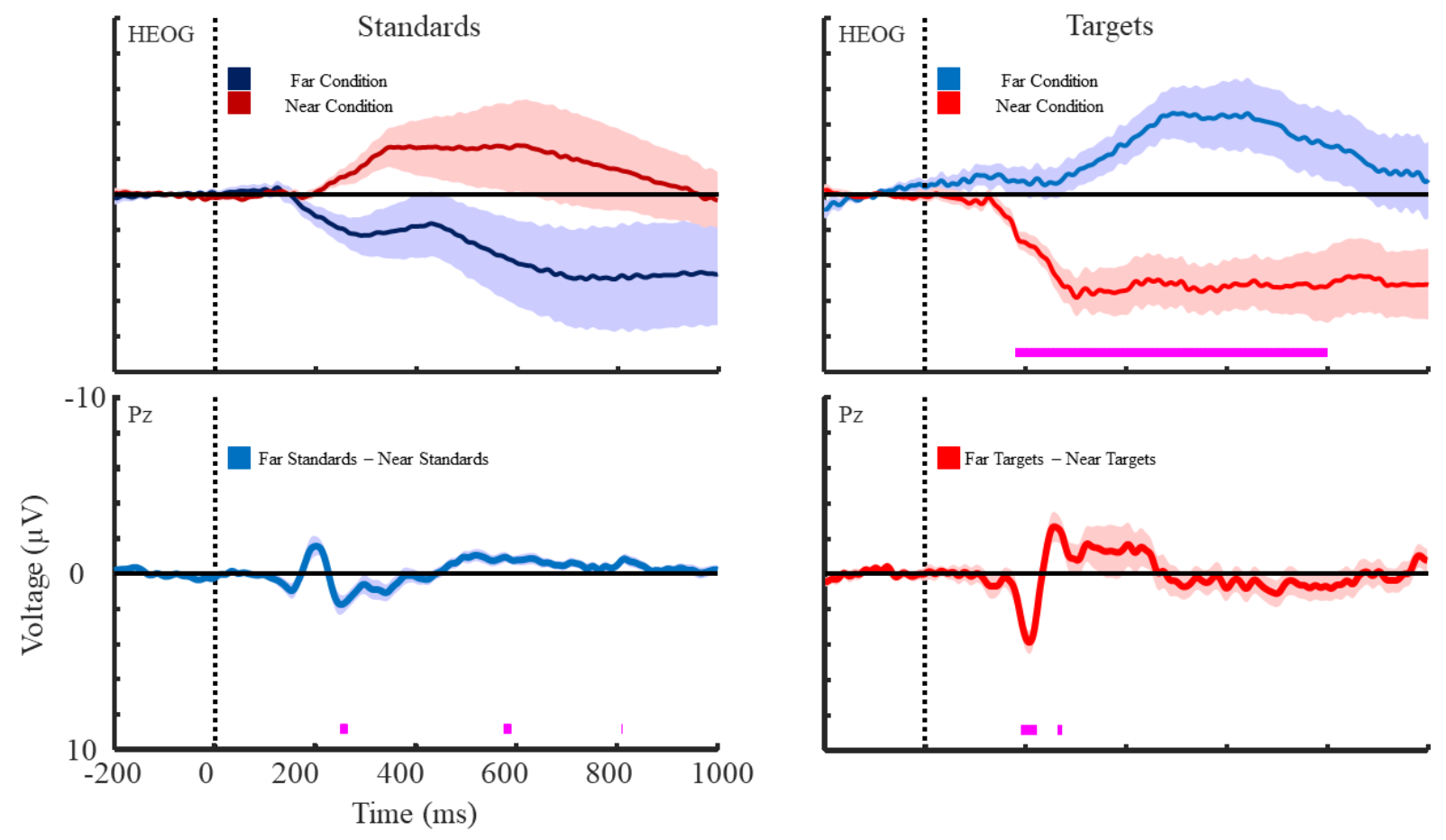